\title{
Modelling the effect of vertical mixing on bottle incubations for determining in situ phytoplankton dynamics. I. Growth rates
}

\author{
Oliver N. Ross ${ }^{1, *}$, Richard J. Geider ${ }^{2}$, Elisa Berdalet ${ }^{3}$, Mireia L. Artigas ${ }^{3}$, Jaume Piera ${ }^{1}$ \\ ${ }^{1}$ Mediterranean Centre for Marine \& Environmental Research, Unidad de Tecnología Marina (UTM, CSIC), \\ Passeig Marítim de la Barceloneta 37-49, 08003 Barcelona, Spain \\ ${ }^{2}$ Dept. Biological Sciences, University of Essex, Wivenhoe Park, Colchester CO4 3SQ, UK \\ ${ }^{3}$ Instituto de Ciencias del Mar (ICM, CSIC), Passeig Marítim de la Barceloneta 37-49, 08003 Barcelona, Spain
}

\begin{abstract}
Reliable estimates of in situ phytoplankton growth rates are central to understanding the dynamics of aquatic ecosystems. A common approach for estimating in situ growth rates is to incubate natural phytoplankton assemblages in clear bottles at fixed depths or irradiance levels and measure the change in chlorophyll a (Chl) over the incubation period (typically $24 \mathrm{~h}$ ). Using a modelling approach, we investigate the accuracy of these Chl-based methods focussing on 2 aspects: (1) in a freely mixing surface layer, the cells are typically not in balanced growth, and with photoacclimation, changes in Chl may yield different growth rates than changes in carbon; and (2) the in vitro methods neglect any vertical movement due to turbulence and its effect on the cells' light history. The growth rates thus strongly depend on the incubation depth and are not necessarily representative of the depth-integrated in situ growth rate in the freely mixing surface layer. We employ an individual based turbulence and photosynthesis model, which also accounts for photoacclimation and photoinhibition, to show that the in vitro Chl-based growth rate can differ both from its carbon-based in vitro equivalent and from the in situ value by up to $100 \%$, depending on turbulence intensity, optical depth of the mixing layer, and incubation depth within the layer. We make recommendations for choosing the best depth for single-depth incubations. Furthermore we demonstrate that, if incubation bottles are being oscillated up and down through the water column, these systematic errors can be significantly reduced. In the present study, we focus on Chl-based methods only, while productivity measurements using carbon-based techniques (e.g. $\left.{ }^{14} \mathrm{C}\right)$ are discussed in Ross et al. $(2011$; Mar Ecol Prog Ser 435:33-45).
\end{abstract}

KEY WORDS: Chlorophyll · Photoacclimation $\cdot$ Photoinhibition $\cdot$ Lagrangian modelling $\cdot$ Individual based modelling $\cdot$ Turbulence $\cdot$ Surface mixing layer $\cdot$ Yo-yo technique

\section{INTRODUCTION}

The relevance of marine phytoplankton as a food for the pelagos and as a potential sink of atmospheric carbon is widely recognised. Marine phytoplankton stands at the base of the pelagic food webs and may act as a potential sink of atmospheric carbon. The ability to determine reliably in situ phytoplankton primary productivity and growth is crucial for understanding the dynamics of aquatic ecosystems, for climate predictions, and for the management of water quality. While primary production measurements try to quantify the conversion of sunlight and inorganic substances into organic compounds in units of grams carbon per unit time and unit area or volume, the growth rates express the increase in the phytoplankton population in units of inverse time. Typical approaches for productivity measurements include the ${ }^{14} \mathrm{C}$ and $\mathrm{O}_{2}$ methods (Williams et al. 1983), while growth rates are sometimes inferred from the changes in total cell numbers (Rhee \& Gotham 1981, Kagami \& Urabe 2001), or-more commonly - total chlorophyll a (Chl) (Landry \& Hassett 1982, Bienfang \& Takahashi 1983, Calbet \& Landry 2004) or taxon-specific pigments (Latasa et al. 1997). 
Current knowledge and technology do not permit us to accurately determine the real in situ growth in natural cells that move freely through the water column. A wide range of sophisticated in vitro methods have been developed to measure phytoplankton growth rates at a species or group level (Stolte \& Garcés 2006). A common approach is to place a natural population into a closed container (polycarbonate bottle or carboy) and to determine the increase in phytoplankton Chl during the incubation period (e.g. Bienfang \& Takahashi 1983, Furuya et al. 1986, Furnas 1990). Since this method only delivers the net growth of the population, it was further refined to the so-called dilution method (Landry \& Hassett 1982, Landry et al. 1995) to provide additional information on the gross growth rate and thus the grazing pressure (see Calbet \& Landry 2004, Behrenfeld 2010, Gutiérrez-Rodríguez et al. 2010, and references therein).

The sampling bottles are often incubated at a single fixed depth (light level), typically the same depth where the samples were taken. Fixed-depth bottle incubations do not necessarily provide a good representation of the temporal and spatial variability in the physical underwater environment, however, as phytoplankton is constantly being moved through the surface mixing layer (SML) (Lewis et al. 1984b) and cells become exposed to a wide range of light intensities (see Fig.1 in Ross et al. 2008). Phytoplankton organisms possess a number of mechanisms to cope with the stresses imposed by fluctuating light (MacIntyre et al. 2000). Amongst the best understood of these mechanisms are photoacclimation, which involves changes in cellular pigment content, and photoprotection, which involves reducing the efficiency of excitation energy transfer from pigments to reaction centres (Falkowski 1983, Lewis et al. 1984a, Geider et al. 1998). Failure to alleviate the light stress by photoacclimation and/or photoprotection may result in photoinhibition of photosynthesis and, in extreme cases, cell death (Eilers \& Peeters 1988, Long et al. 1994, Behrenfeld et al. 1998, Ross et al. 2008). These processes are relevant to assessing phytoplankton growth from incubation experiments, because the overall performance (growth) of a cell, as well as the relationship between chlorophyll synthesis, photosynthesis, and cell growth will vary markedly with the cell's light history. One problem that must be faced by the experimentalist is to determine at which depth in the water column (e.g. at which light level) to conduct an incubation in order to obtain accurate measurements of the in situ growth rate.

The problem in using fixed-depth/irradiance bottle incubation experiments to estimate the in situ growth rate is thus 2 -fold.

(1) Differences between growth rates estimated from changes in chlorophyll concentration and carbon: A sample of a natural phytoplankton population that is taken from a single depth will contain cells with different light histories and thus different photoacclimation states (e.g. different Chl:C and different degrees of photoinhibition). Very rarely will a particular cell be fully adapted to the light intensity at the depth at which it is found at a given instant in time (see Fig. 3). By incubating cells at a fixed depth, their residence time at the incubation depth is artificially increased, which provides the opportunity to (1) photoacclimate to the ambient light level, resulting in uncoupling of chlorophyll synthesis from $\mathrm{CO}_{2}$ fixation, (2) accumulate photoinhibitory damage if cells are incubated at high light intensities too close to the surface, or (3) repair photoinhibitory damage when incubated at low light deeper in the water column. In general, it is therefore not justified to assume that phytoplankton growth is balanced, i.e. that the increase in chlorophyll is matched by the increase in carbon so that the former may be used as proxy for the determination of the carbon-based growth rate $\mu_{C}$. Although most experimentalists are aware of this problem (Brown et al. 2002, Latasa et al. 2005, Gutiérrez-Rodríguez et al. 2010) it remains difficult to provide an accurate quantification of the associated error.

(2) The growth rate varies with incubation depth and may not be representative of the entire $S M L$ : It is not clear a priori, that cells incubated at a single fixed depth (and thus at relatively stable light conditions) should grow at a rate that is representative of the entire layer. Particularly in coastal areas or estuaries, where strong turbulent mixing in combination with high light attenuation coefficients may subject the cells to large and rapid changes in light intensity (e.g. Lizon et al. 1998, Sharples et al. 2001, Moore et al. 2006, Ross \& Sharples 2007), or during deep mixing events in the open ocean in winter and spring (e.g. Fig. 1 in Ross et al. 2008, Woods \& Onken 1982, Nagai et al. 2003), the associated error can become quite large. Alternative approaches have been devised which aim to alleviate this problem by simulating the large-scale vertical displacements due to turbulence by moving the incubation bottles up and down through the water column or using on-deck incubators that expose the samples to variations in light intensity (Marra 1978, Köhler 1997, Köhler et al. 2001, Gocke \& Lenz 2004). While both the yo-yo technique and the linear incubator appear to be promising approaches to overcome the limitations associated with fixed-depth incubations, they both come with the caveat that the choice of the amplitude and period of the vertical oscillations/light variations is an ad hoc decision which is often taken without much prior knowledge of the in situ mixing conditions.

In the present study we employ a state-of-the-art individual-based model of turbulence and phytoplank- 
ton growth, acclimation, and inhibition to compare the Chl-based growth rates obtained from fixed-depth bottle incubations with the carbon equivalent and the growth rates obtained for a population that was freely mixing in the SML. As it is currently not possible to measure the in situ growth rate of a freely mixing phytoplankton population non-intrusively, the use of a model seems the best approach. The model consists of 2 components: (1) a Lagrangian turbulence module, which provides the individual particle tracks and associated light histories in response to turbulence mixing, and (2) a biological module, which calculates the growth rates based on the individual light histories, taking into account photoacclimation and photoinhibition. The Lagrangian technique (Woods \& Onken 1982, Wolf \& Woods 1988, Lizon et al. 1998, Broekhuizen 1999, Ross \& Sharples 2007) seems a natural choice to approach this problem, as its Eulerian counterpart cannot provide the necessary information on the individual light histories. We simulate shallow and deep, turbid and clear, turbulent and quiescent water columns in order to quantify the differences between the growth rates for a range of natural environments. We propose remedies and recommendations for the experimental protocol that will help to minimise the errors associated with fixed-depth incubations. We also examine the extent to which a vertically oscillating bottle incubation can deliver more accurate estimates of the in situ growth rates. In a companion paper (Ross et al. 2011, this volume), we investigate how fixed depth incubations affect estimates of primary productivity, which are usually based on ${ }^{14} \mathrm{C}$ in a series of incubations that are suspended at fixed depths throughout the mixing layer.

\section{METHOD}

With the vertical being the key dimension for our problem it is sufficient to employ a $1 \mathrm{D}$ vertical physicalbiological model. Each of the 2 main components (the Lagrangian model and the biological module) is described in more detail in the following sections.

All simulations run for a total of $5 \mathrm{~d}$ ( $4 \mathrm{~d}$ of spin-up plus $1 \mathrm{~d}$ for measuring) and the particles are mixed using an eddy diffusivity in combination with a random walk approach (see below). In the runs which simulate the fixed-depth bottle incubations, the turbulent mixing is switched off at the beginning of the 5th day and all particles remain 'frozen' in place for $24 \mathrm{~h}$. We then compare the growth rates, both within each depth bin and integrated over the entire layer, during the incubation period to the growth rates from the runs where particles were freely mixing on the 5th day. Both sets of experiments that were run for each scenario thus share the same $4 \mathrm{~d}$ spin-up and only differ on the last day.

Unless stated otherwise, all experiments used the same peak mid-day incident irradiance of $650 \mathrm{~W} \mathrm{~m}^{-2}$, $45 \%$ of which is considered to be photosynthetically active radiation (PAR). This leaves a surface mid-day PAR of about $I_{m}=1200 \mu \mathrm{mol}$ photons $\mathrm{m}^{-2} \mathrm{~s}^{-1}$ that decreases exponentially with depth as

$$
I(z)=I(z=0) \mathrm{e}^{k z}=I(z=0) \mathrm{e}^{-\xi}
$$

where $k$ is the PAR attenuation coefficient and $z$ is the depth $(z<0)$ in metres. The light availability thus always depends on the product of $k$ and $-z$, which is the optical depth $\xi$. We therefore express the vertical dimension in our figures in terms of $\xi$. Over the course of the light period ( $15 \mathrm{~h}$ per $24 \mathrm{~h}$ ) the surface irradiance $I(z=0)$ was varied using a semi-sinusoidal modulation.

Note that the term surface mixing layer (SML) denotes the isothermal or isopycnal layer which is actively mixing, i.e. where the eddy diffusivity is consistently higher than some background value. It is thus a purely physical definition and does not imply that the layer is fully mixed in a biological sense such that the physiology would be homogeneous throughout the layer. This would depend on the ratio of the physical mixing time-scale versus the biological time-scales of photoacclimation, -inhibition, and growth (see the discussion in Ross et al. 2011, Lewis et al. 1984b). While most mixing layers will have mixing time scales $(\tau)$ of the order of hours to few days, we also found reports of mixing layers with mixing time scales $\left(\tau_{m}\right)$ of the order of thousands of hours. In Table 1 of Gallegos \& Platt (1985), for instance, the diffusivity at a station in the oligotrophic ocean was reported as $10^{-5} \mathrm{~m}^{2} \mathrm{~s}^{-1}$. While nothing is said about the depth of the SML, we would obtain a mixing time scale of $2500 \mathrm{~h}$ for a shallow SML of $10 \mathrm{~m}$. Such a layer can only remain mixed if it is overturned at night due to convective instabilities. For scenarios with $\tau_{m}>100 \mathrm{~h}$, we therefore simulated the convective overturning by temporarily increasing the eddy diffusivity $K_{m}$ from its 'normal' daytime value to $10^{-2} \mathrm{~m}^{2} \mathrm{~s}^{-1}$ for $5 \mathrm{~h}$ each night. This was not necessary for scenarios with $\tau_{m} \leq 100 \mathrm{~h}$, as the mixing was sufficient to keep the biomass homogeneously distributed. Table 1 contains a summary of the main model parameters and their standard values.

Lagrangian particle tracking. We represent phytoplankton using an individual based approach, i.e. phytoplankton are not modelled as a concentration of carbon or chlorophyll per unit volume (Eulerian approach) but as individual cells that are moved freely through the water column by turbulence. The advantage of using a Lagrangian approach lies in its ability to record the individual light histories of the cells, which allows for a more accurate simulation of the photo- 
physiological response. The total number of Lagrangian particles in our simulations varied depending on the total water depth. For simulations of shallow water scenarios $(H=6 \mathrm{~m})$, we used 8000 Lagrangian particles, while in deeper water $(H \geq 60 \mathrm{~m})$ we used 80000 . This high number was necessary in order to obtain reliable statistics at each $1 \mathrm{~m}$ depth bin. We distinguish between Lagrangian particles (the number of which stays fixed) and phytoplankton cells (which are allowed to divide and multiply). At the start of an experiment, the Lagrangian particles are homogeneously distributed with depth, and each particle rep- resents the same number of phytoplankton cells (Lagrangian Ensemble approach). Over the course of the experiment, the distribution of Lagrangian particles always remains homogeneous as we assume neutral buoyancy.

Given that most diatoms have sustained sinking speeds of $<3 \mathrm{~m} \mathrm{~d}^{-1}$ (Eppley et al. 1967, Bienfang 1981, Waite et al. 1997, Ptacnik et al. 2003), we decided to neglect diatom sinking altogether, as tests with such sinking velocities did not significantly alter our results. Motility on the other hand, i.e. the ability for directed swimming by dinoflagellates or coccolithophores,

Table 1. Model parameters and meaning of symbols used throughout the text. A list of the remaining model parameters for the biological model can be found in Appendix 1 and Ross \& Geider (2009, their Table 1). SML: surface mixing layer; PAR: photosynthetically active radiation

\begin{tabular}{|c|c|c|c|}
\hline Symbol & Description & Value & Unit \\
\hline$a^{C h l}$ & Chl a specific absorption coefficient & 6.56 & $\mathrm{~m}^{2} \mathrm{gChl}^{-1}$ \\
\hline$C^{F}$ & Amount of carbon in functional pool & Variable & gC cell ${ }^{-1}$ \\
\hline$C$ & Total amount of carbon in cell & Variable & gC cell ${ }^{-1}$ \\
\hline Chl & Amount of chlorophyll $a$ in cell & Variable & $\mathrm{gChl} \mathrm{cell}^{-1}$ \\
\hline$D$ & Depth of water column (model domain) & Variable & $\mathrm{m}$ \\
\hline$H$ & SML thickness & Variable & $\mathrm{m}$ \\
\hline$I$ & Light intensity & Variable & $\mu \mathrm{mol}$ photons $\mathrm{m}^{-2} \mathrm{~s}^{-1}$ \\
\hline$I_{k}$ & Light saturation parameter & Variable & $\mu \mathrm{mol}$ photons $\mathrm{m}^{-2} \mathrm{~s}^{-1}$ \\
\hline$k$ & PAR attenuation coefficient & Variable & $\mathrm{m}^{-1}$ \\
\hline$k_{r}$ & Repair rate from photoinhibition & $4.5 \times 10^{-5}$ & $\mathrm{~s}^{-1}$ \\
\hline$k_{d}$ & Damage probability for photoinhibition & $1.4 \times 10^{-7}$ & - \\
\hline$K$ & Turbulent diffusivity & Variable & $\mathrm{m}^{2} \mathrm{~s}^{-1}$ \\
\hline$K_{\mathrm{bg}}$ & Background turbulent diffusivity below SML & $10^{-5}$ & $\mathrm{~m}^{2} \mathrm{~s}^{-1}$ \\
\hline$K_{m}$ & Mid SML turbulent diffusivity & Variable & $\mathrm{m}^{2} \mathrm{~s}^{-1}$ \\
\hline$K_{\text {surf }}$ & Turbulent diffusivity at surface boundary & $0.1 K_{m}$ & $\mathrm{~m}^{2} \mathrm{~s}^{-1}$ \\
\hline$P_{\max }^{\text {cell }}$ & Max. cell-based C production & Variable & $\mathrm{gC} \mathrm{cell}^{-1} \mathrm{~s}^{-1}$ \\
\hline$P_{m}^{c h l}$ & Max. Chl-based C production (with inhibition) & $P_{\max }^{c h l} \vartheta$ & $\mathrm{gC} \mathrm{gChl}^{-1} \mathrm{~s}^{-1}$ \\
\hline$P_{\max }^{c h l}$ & Max. Chl-based C production (without inhibition) & $3.3 \times 10^{-3}$ & $\mathrm{gC} \mathrm{gChl}^{-1} \mathrm{~s}^{-1}$ \\
\hline$P_{\max }^{F}$ & Max. carbon-based production at a given $\mathrm{N}: \mathrm{C}$ & Variable & $\mathrm{s}^{-1}$ \\
\hline$z$ & Particle position & $<0$ & $\mathrm{~m}$ \\
\hline$\alpha_{\max }^{C h l}$ & Initial slope of the P-I curve (without inhibition) & $6.3 \times 10^{-6}$ & $\mathrm{gC} \mathrm{m}^{2}(\mathrm{gChl} \mu \mathrm{mol} \text { photons })^{-1}$ \\
\hline$\Delta t$ & Model time step & $1-6^{\mathrm{a}}$ & $\mathrm{s}$ \\
\hline$\varepsilon_{1}$ & Error between $\mu_{C h l}^{\text {incub }}$ and $\mu_{C}^{\text {incub }}$ & Variable & $\%$ \\
\hline$\varepsilon_{2}$ & Error between $\mu_{C h l}^{\text {incub }}$ and $\mu_{C}^{\text {mixed }}$ & Variable & $\%$ \\
\hline$\phi_{\max }$ & Max. quantum yield of photosynthesis & $0.96 \times 10^{-6}$ & $\mathrm{gC}(\mu \mathrm{mol} \text { photons })^{-1}$ \\
\hline$\phi_{m}$ & Achieved quantum yield when inhibited & Variable & $\mathrm{gC}(\mu \mathrm{mol} \text { photons })^{-1}$ \\
\hline$\mu_{x}^{\text {incub }}$ & $\mathrm{x}$-derived growth rates from incubations & Variable & $d^{-1}$ \\
\hline$\mu_{x}^{\text {mixed }}$ & $\mathrm{x}$-derived depth-integrated growth rates from turbulent water & Variable & $d^{-1}$ \\
\hline$\Pi_{\max }^{L}$ & Max. prop. of $C^{F}$ allocated to light harvesting & 0.33 & - \\
\hline$\theta^{C}$ & $\mathrm{Chl}: \mathrm{C}$ ratio of cell & Variable & $\mathrm{gChl} \mathrm{gC}^{-1}$ \\
\hline$\theta_{F}^{C}$ & Chl:C ratio for functional pool only & Variable & $\mathrm{gChl} \mathrm{gC}^{-1}$ \\
\hline$\left(\theta_{L}^{C}\right)_{\max }$ & Max Chl:C ratio in light-harvesting pool & 0.28 & $\mathrm{gChl} \mathrm{gC}^{-1}$ \\
\hline$\vartheta$ & Proportion of functional PSII reaction centres & $0 \leq \vartheta \leq 1$ & - \\
\hline$\sigma_{\text {PSII }}$ & Absorption cross-section of PSII & 1.5 & $\mathrm{~m}^{2}(\mu \mathrm{mol} \text { photons })^{-1}$ \\
\hline$\xi$ & Optical depth within water column & Variable & - \\
\hline$\xi_{\mathrm{SML}}$ & Optical depth of the surface mixing layer & Variable & - \\
\hline$\tau_{m}$ & Mixing time scale of surface mixing layer & Variable & $\mathrm{h}$ \\
\hline
\end{tabular}


could potentially alter our results as different swimming strategies may lead to highly inhomogeneous particle concentrations (turbulence permitting) and thus growth rates different from those obtained for a homogeneously distributed population. As any choice of swimming strategy (phototactic, geotactic, etc.) would have to be made arbitrarily, we omitted motility from our analysis. Because the main goal of this work was to evaluate whether vertical mixing by turbulence can be neglected for the determination of growth rates, i.e. whether a fixed depth bottle incubation delivers results that are representative of a freely mixing water column, we could also neglect factors such as nutrients or grazing, as their absence or presence would have the same effect on both the stranded and freely mixing populations. We also did not concern ourselves with other sources of error, such as bottle effects, which have already been addressed elsewhere (see Furnas 2002, for a review).

The one-dimensional (vertical) particle-tracking model is based on Ross \& Sharples (2004). Vertical profiles of the eddy diffusivity, $K(z)\left(\mathrm{m}^{2} \mathrm{~s}^{-1}\right)$ (see below), in combination with a random walk approach were used to provide the random, turbulent mixing of Lagrangian particles. At each time step, $\Delta t$, a particle was moved from its present position, $z_{n}$, to its new position, $z_{n+1}$, using:

$$
z_{n+1}=z_{n}+\underbrace{K^{\prime}\left(z_{n}\right) \Delta t}_{\text {deterministic term }}+\underbrace{\left[\frac{2 K\left(z_{n}+\frac{1}{2} K^{\prime}\left(z_{n}\right) \Delta t\right) \Delta t}{r}\right]^{1 / 2}}_{\text {random term }}
$$

where $K^{\prime}=\mathrm{d} K / \mathrm{d} z . R$ is a random process of zero mean and variance $r$ (e.g. $r=1 / 3$ for $R \in[-1,1]$ ). The top and bottom boundaries were reflecting according to

$$
z_{n+1} \rightarrow\left\{\begin{array}{cl}
-z_{n+1} & , \text { if } z_{n+1}>0 \\
2 H+z_{n+1} & \text {, if } z_{n+1}<-D
\end{array}\right.
$$

where $H$ is the depth of the SML and $D$ is the total depth of the water column.

We created a physical environment based both on observational (e.g. Sharples et al. 2001) and modelling results (e.g. Ross \& Sharples 2007) of a turbulent SML, which fulfils all necessary requirements for use with the random walk in terms of differentiability, steadiness, and reflecting boundary conditions (cf. Ross \& Sharples 2004). The resulting diffusivity profile is constant throughout most of the mixing layer. The transitional areas where the diffusivity is allowed to decrease in a continuous and differentiable fashion towards the top and bottom boundaries are designed to deliver a time step greater than $1 \mathrm{~s}$ in the random walk while keeping the error below $1 \%$ (cf. Ross \& Sharples 2004). The profile is constructed as follows:

$$
\begin{aligned}
& K(z)= \\
& \begin{cases}K_{\text {surf }}+\left(K_{m}-K_{\text {surf }}\left[1-1.5^{-|z|^{2.3}}\right]\right. & \text { for } 0 \geq z>-H / 2 \\
K_{\mathrm{bg}}+\left(K_{m}-K_{\mathrm{bg}}\right)\left[1-1.5^{-(H+z)^{2.3}}\right] & \text { for }-H / 2 \geq z \geq(-H) \\
K_{\mathrm{bg}} & \text { for } z<-H\end{cases}
\end{aligned}
$$

where $K_{\mathrm{bg}}$ is the background diffusivity in the stratified area below the SML, and $K_{\text {surf }}$ is the near surface diffusivity, which was set to between 20 and $90 \%$ of the mid-SML value $K_{m}$, depending on the profile. The Roman numerals in Eq. (4) denote the 3 different segments of the profile: [I] top half of SML, [II] lower half of SML, and [III] below the SML (cf. Fig. 1).

We tested a wide range of environmental scenarios using different combinations of attenuation coefficients, mixing layer depths, and turbulent eddy diffusivities. The physical environment can be characterised using 2 important parameters, namely the mixing time scale, $\tau_{m}$, and the optical depth of the SML, $\xi_{\mathrm{SML}}$, which are given by:

$$
\tau_{m}=\frac{H^{2}}{K_{m}} \quad \text { and } \quad \xi_{\mathrm{SML}}=H k
$$

where $H$ is the SML depth and $K_{m}$ the maximum (midSML) eddy diffusivity. Fig. 2 provides a visual representation of the effect of different mixing time scales on the change of a particle distribution with time.

Biological model. The biological model used in the simulations is based on the RG ${ }^{\mathrm{I}}$ model in Ross \& Geider (2009). Rather than being solely carbon-based, the biological model employs the cell as the basic unit, which is a more natural choice for use in individual-based modelling approaches such as this one. The model differentiates between a nitrogen-containing functional carbon pool and an energy reserve pool, which does

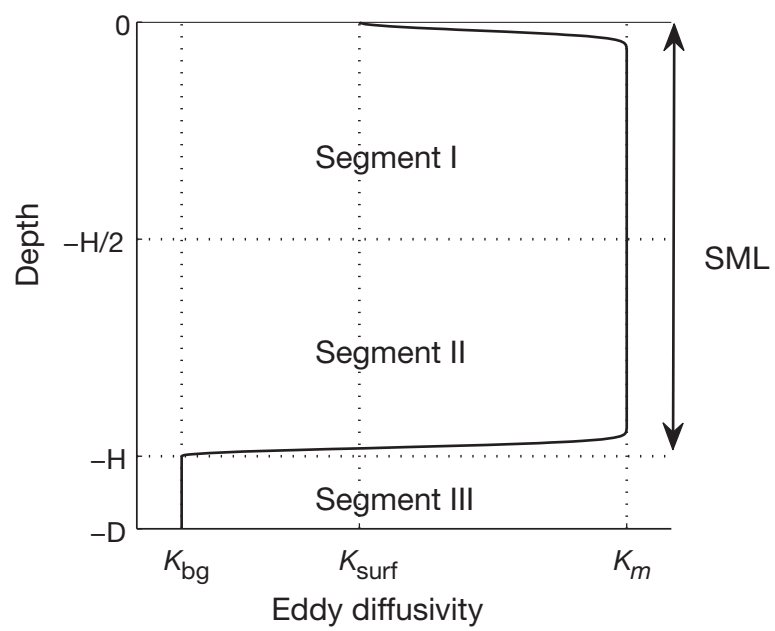

Fig. 1. Example diffusivity profile where the Roman numerals denote the 3 different segments from Eq. (4) 
not contain nitrogen. The cell-specific light-saturated photosynthetic rate is assumed to scale with the size of the functional pool, and the light-limited photosynthesis rate with the cellular chlorophyll content. The model has been validated against data from light shift experiments on Skeletonema costatum (Anning et al. 2000, Ross \& Geider 2009) and the values of the growth and acclimation parameters we use in this study are representative of this diatom. As we are not concerned about absolute growth rates but content ourselves with comparative analyses, the results presented in this study are insensitive to small changes in these parameter values and are therefore deemed to be valid for a wider range of phytoplankton species. Although we made some modifications to the $\mathrm{RG}^{\mathrm{I}}$ model and added new equations to account for photoinhibition, most of the model equations are unchanged. We therefore do not re-iterate the entire model description but limit our description to the new and modified parts of the model. A complete set of the biological model equations, including the unchanged parts from the original $\mathrm{RG}^{\mathrm{I}}$ model, is contained in Appendix 1 (see Ross \& Geider 2009 for additional information).

We extend the RGI model from Ross \& Geider (2009) to account for photoinhibition using a similar approach as in Cianelli et al. (2004) except that we apply the inhibition primarily to the initial slope of the photosynthesis-light curve, $\alpha^{C h l}$, and only once the damage becomes more substantial also to the maximum cellbased carbon production, $P_{\max }^{\text {cell }}$. The proportion of still functional reaction centres, $\vartheta$, depends on the damage probability, $k_{d}$ and the recovery rate, $k_{r}$ of the D1 protein as (cf. Han 2002, Cianelli et al. 2004):

$\frac{\mathrm{d} \vartheta}{\mathrm{d} t}= \begin{cases}-k_{d} \sigma_{\mathrm{PSII}} I \vartheta\left(1-\frac{P^{\mathrm{cell}}\left(\phi_{\max }\right)^{-1}}{I a^{C h l} C h l}\right)+k_{r}(1-\vartheta) & , \text { if } I>0 \\ k_{r}(1-\vartheta) & \text {, if } I=0\end{cases}$ (a) $\tau_{m}=1 \mathrm{~h}$
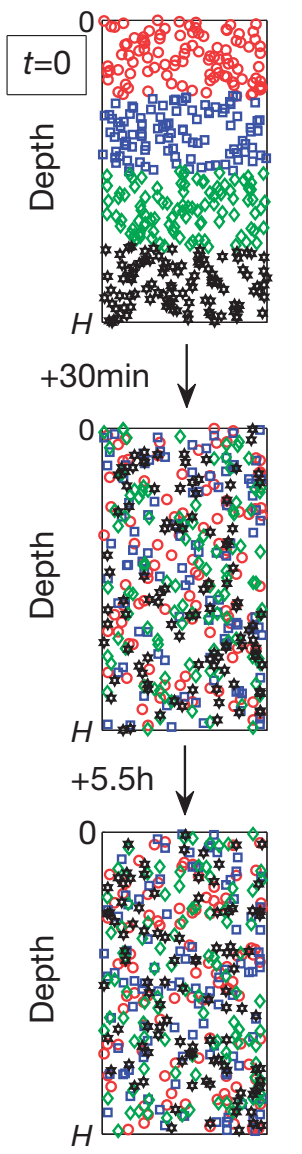

(b) $\tau_{m}=10 \mathrm{~h}$
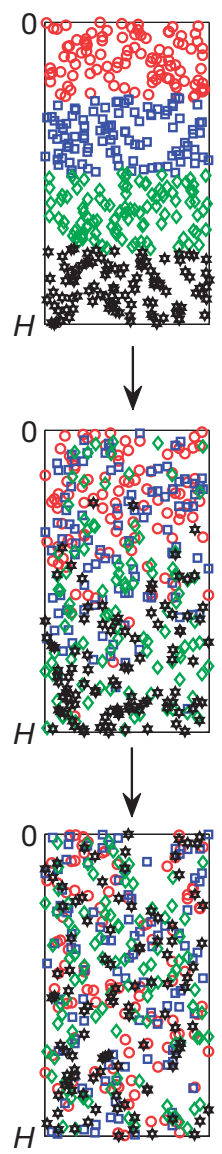

(c) $\tau_{m}=100 \mathrm{~h}$
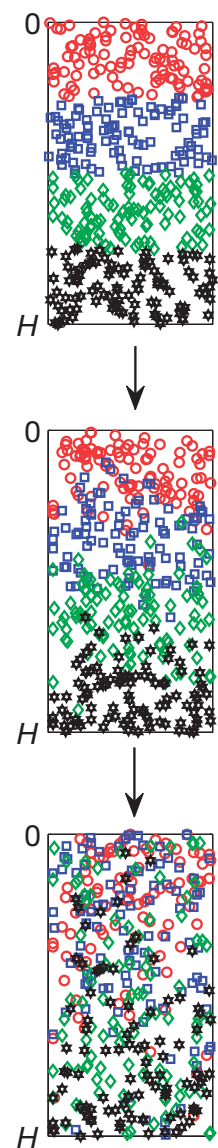

(d) $\tau_{m}=1000 \mathrm{~h}$

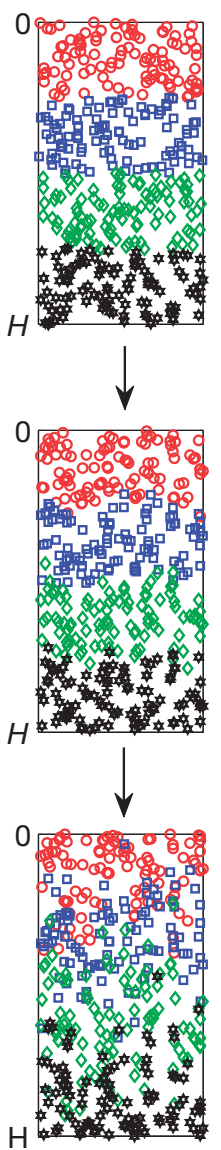

Fig. 2. Effect of the mixing time scale $\tau_{m}$ on the vertical particle distributions over the course of time. The top row shows the initial conditions at time $t=0$, the middle row is after $30 \mathrm{~min}$ into the simulation, and the bottom row shows the particles after another $5.5 \mathrm{~h}$, i.e. $6 \mathrm{~h}$ after the start of the experiment. The particles were assigned a certain marker and colour depending on their initial position in the water column

where $\sigma_{\mathrm{PSII}}$ is the absorption cross-section of Photosystem II (PSII), $a^{C h l}$ the Chl specific absorption coefficient and $\phi_{\max }$ the maximum quantum yield of photosynthesis (Table 1). The values chosen for $k_{d}$ and $k_{r}$ from Table 1 are based on Cianelli et al. (2004), while the values for $\sigma_{\mathrm{PSII}}$ and $\phi_{\max }$ are based on Suggett et al. (2009) and MacIntyre et al. (2002), respectively. The value of $a^{C h l}$ was determined experimentally for Thalassiosira pseudonana (Ross \& Geider 2009). The parameter $\vartheta$ describes the proportion of still functional PSII reaction centres (RCII) $(0 \leq \vartheta \leq 1)$ with the extremes of $\vartheta=1$ corresponding to zero inhibition (i.e. all centres are functional) and the theoretical value of $\vartheta=0$ corresponding to $100 \%$ inhibition (with no functional centres remaining). We expect the probability of photoinhibition (per photon absorbed) to be greater when photosynthesis is light saturated and almost all of the reaction centres are closed than when photosynthesis is light limited and almost all of the reaction centres are open. This is expressed by the term

$$
\left(1-\frac{P^{\text {cell }}\left(\phi_{\max }\right)^{-1}}{I a^{C h l} C h l}\right)
$$

in Eq. (6) which is a proxy for reaction centre closure. The denominator is the rate of light absorption by the cell (photons per cell per unit time) and the numerator is the rate of use of photons for photosynthesis.

When the maximum quantum efficiency of photosynthesis, $\phi_{\max }$ is determined by the 
maximum quantum efficiency of PSII, we expect the initial slope of the photosynthesis-light curve, $\alpha^{C h l}$, to be given by:

$$
\alpha^{C h l}=\phi_{m} a^{C h l}=\phi_{\max } \vartheta a^{C h l}=\alpha_{\max }^{C h l} \vartheta
$$

Hence instead of Eq. (14) from Ross \& Geider (2009) we obtain the following modified equation for the cell based production:

$$
P^{\text {cell }}=P_{\max }^{\text {cell }}\left[1-\mathrm{e}^{-\left(I \alpha^{C h l} C h l / P_{\max }^{\text {cell }}\right)}\right]
$$

Previous work suggested that photoinhibition not only affects the initial slope $\alpha^{C h l}$ but also the light saturated maximum production $P_{\max }^{\text {cell }}$ (Behrenfeld et al. 1998). We implemented this by changing Eq. (15) from Ross \& Geider (2009) to the following minimum condition:

$$
P_{\max }^{\text {cell }}=\operatorname{MIN}\left\{\begin{array}{l}
P_{\max }^{F} C^{F} \\
P_{m}^{\text {chl }} C h l
\end{array}\right.
$$

where $C^{F}$ and $C h l$ are the amounts of functional carbon and chlorophyll per cell, respectively. $P_{\max }^{F}$ is the maximum carbon-based production at a given nitrogen-tocarbon ( $\mathrm{N}: \mathrm{C})$ ratio and $P_{m}^{c h l}$ is the maximum Chl-based carbon production at a given inhibition level:

$$
P_{m}^{c h l}=P_{\max }^{c h l} \vartheta
$$

Implicit in Eq. (9) is the assumption that control of the light saturated photosynthesis rate may lie either in the light-reactions (e.g. in the photosynthetic electron transfer chain) or the dark-reactions (e.g. in the Calvin cycle) of photosynthesis. Light saturated photosynthesis is often limited by the dark-reactions (Sukenik et al. 1987). However, when $P_{m}^{c h l} C h l<P_{\max }^{F} C^{F}$, the light reactions will be limiting. Control of the light-saturated photosynthesis is likely to be transferred from the dark-reactions to the light-reactions as a consequence of photoinhibition. Falkowski (1981) calculated a theoretical maximum value for $P_{\max }^{c h l}$ of $24 \mathrm{gC}(\mathrm{gChl})^{-1} \mathrm{~h}^{-1}$ for ambient water temperatures of $25^{\circ} \mathrm{C}$. Given that photosynthetic electron transfer reactions have a $Q_{10}$ of about 2 (Raven \& Geider 1988), the value can be scaled for environmental temperature: so at $15^{\circ} \mathrm{C}$ it would be 12 , whereas at $5^{\circ} \mathrm{C}$ it would be $6 \mathrm{gC}(\mathrm{gChl})^{-1} \mathrm{~h}^{-1}$. In our model we used a value of $P_{\max }^{c h l}=12 \mathrm{gC}(\mathrm{gChl})^{-1} \mathrm{~h}^{-1}$.

The parametrisation of the effect of photoinhibition of the light saturated photosynthesis in Eq. (9) is based on the observation that phytoplankton possess an 'excess' PSII capacity (Behrenfeld et al. 1998). The first part in Eq. (9) is identical to Eq. (15) from Ross \& Geider (2009) and describes the light saturated photosynthesis in the absence of photoinhibition. Hence, initially, $P_{\max }^{\text {cell }}$ will not be affected as the product $P_{\max }^{F} C^{F}$ will be lower than $P_{m}^{\text {chl }} \mathrm{Chl}$. Once photoinhibition increases, however, the proportion of functional RCII, $\vartheta$, will decrease, as will also $P_{m}^{\text {chl }}$ (Eq. 10). This parametrisation is consistent with the observation that the quantum efficiency is decreased by damage to PS II (Öquist et al. 1992), and Eqs. (8) \& (9) are loosely based on Fig. 1 of Behrenfeld et al. (1998).

Quantification of errors. For the analyses we focus on comparing the Chl-derived growth rate from fixeddepth bottle incubations, $\mu_{C h l}^{\text {incub }}$, with its carbon-derived equivalent, $\mu_{C}^{\text {incub }}$, and the carbon-based growth rate in the freely mixed water column, $\overline{\mu_{C}^{\text {mixed }}}$, which we will refer to as the in situ growth rate. In accordance with the interests of experimentalists, we consider the depth-averaged carbon growth rate in the SML, which

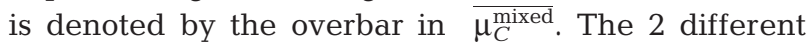
errors to be considered are thus $\varepsilon_{1}$, the error due to using $\mathrm{Chl}$ as a proxy for measuring growth, and $\varepsilon_{2}$, the error due to arresting the cells at a single fixed depth during the incubation:

$$
\varepsilon_{2}(z)=\frac{\mu_{C h l}^{\text {incub }}(z)-\overline{\mu_{C}^{\text {mixed }}}}{\overline{\mu_{C}^{\text {mixed }}}} \cdot 100 \%
$$

where the growth rates are calculated from:

$$
\begin{aligned}
& \mu_{X}(z)=\ln \left(\frac{X\left(z, t_{1}\right)}{X\left(z, t_{0}\right)}\right) \frac{1}{T} \\
& \text { and } \\
& \overline{\mu_{X}}=\ln \left(\frac{\sum_{z=0}^{-H} X\left(z, t_{1}\right)}{\sum_{z=0}^{-H} X\left(z, t_{0}\right)}\right) \frac{1}{T}
\end{aligned}
$$

with $T=t_{1}-t_{0}$ being the incubation period $(24 \mathrm{~h})$.

Simulating the yo-yo approach. One question which may be interesting for experimentalists is whether changes in the experimental protocol, e.g. by oscillating the incubation bottles vertically through the SML, can mitigate some of errors observed in fixed depth incubations. In order to address this question we used the same model setup as before, with the exception that the cells are not arrested at fixed depths during the $24 \mathrm{~h}$ incubation period, but the cells within a particular depth bin are collectively moved up and down through the water column at a pre-determined velocity $w_{\text {yo-yo }}$. The choice of $w_{\text {yo-yo }}$ is to some extent arbitrary and was based on the standard deviation (SD) of the random walk which increases with time as (Ross \& Sharples 2004):

$$
\Sigma(t)=\sqrt{2 K_{m} t}
$$

To obtain some estimate of $\Sigma$ at longer time scales we evaluated Eq. (13) for $t=1 \mathrm{~h}$. This yields the SD in metres of a distribution of particles that was originally located at a point source $z=0$. In order to convert this into a velocity we used

$$
W_{\text {yo-yo }}=0.55 \frac{\Sigma(t=1 \mathrm{~h})}{1 \mathrm{~h}}
$$

For the example of $10^{-2} \mathrm{~m}^{2} \mathrm{~s}^{-1}$ this yields $W_{\mathrm{yo}-\mathrm{yo}} \approx$ $4.6 \mathrm{~m} \mathrm{~h}^{-1}$. The scaling factor of $0.55 \mathrm{in}$ Eq. (14) resulted 
from tests with a range of environmental conditions. Particularly in experiments where the diffusivity was low, we noticed that without the scaling factor, Eq. (14) would overestimate the vertical velocities, yielding a vertically too homogeneous growth rate compared to the mixed conditions. The choice of this scaling factor is based on a best fit analysis for a range of experiments to minimise the errors in the shape and magnitude of the growth rates. For water columns where the turbulence is high, an overestimation of $w_{\text {yo-yo }}$ is not too critical, as the growth rate is already homogeneous with depth and the magnitude of the growth rate is not affected by an overestimation.

\section{RESULTS}

While an Eulerian model always has uniform physiologies in each depth bin as it implicitly averages over the individuals, the Lagrangian counterpart can provide much more detailed information, including the amount of heterogeneity within a $1 \mathrm{~m}$ depth element due to cells with different light histories having been mixed together by turbulence. When the cells are freely mixing, weak turbulence (Fig. 3a) leads to a distribution of $\mathrm{Chl}: \mathrm{C}$ that is rather heterogeneous, both vertically and also within a depth bin. At high turbulence intensities (Fig. 3b), Chl:C is more uniform, both within and between depth bins, as the cells do not have enough time to acclimate to any particular light level. While Fig. 3a provides a good example of a surface mixing layer that is not mixed in the biological sense, Fig. $3 \mathrm{~b}$ shows a surface layer that is not only mixing but also mixed, with little vertical heterogeneity in the physiology.

When the cells are kept at fixed depths to simulate the bottle incubation, their residence time at each light level is greatly increased, allowing them to acclimate to the ambient light. As a result, the vertical heterogeneity in Chl:C is increased, while only a small heterogeneity is maintained within each depth bin (Fig. 3c,d).

\section{Growth rates}

Throughout the SML, but particularly near the surface, the 2 growth rates, $\mu_{C h l}^{\text {incub }}$ and $\mu_{C}^{\text {incub }}$, differ considerably from one another (Fig. 4). Near the surface $\mu_{C h l}^{\text {incub }}$ is lower than $\mu_{C}^{\text {incub }}$, due to photoacclimation, and $\varepsilon_{1}$ is negative there (Fig. $4 \mathrm{~b}, \mathrm{~d}, \mathrm{f}, \mathrm{h}$ ). In samples incubated at high light, Chl synthesis is reduced while carbon uptake remains high, which causes a shift in
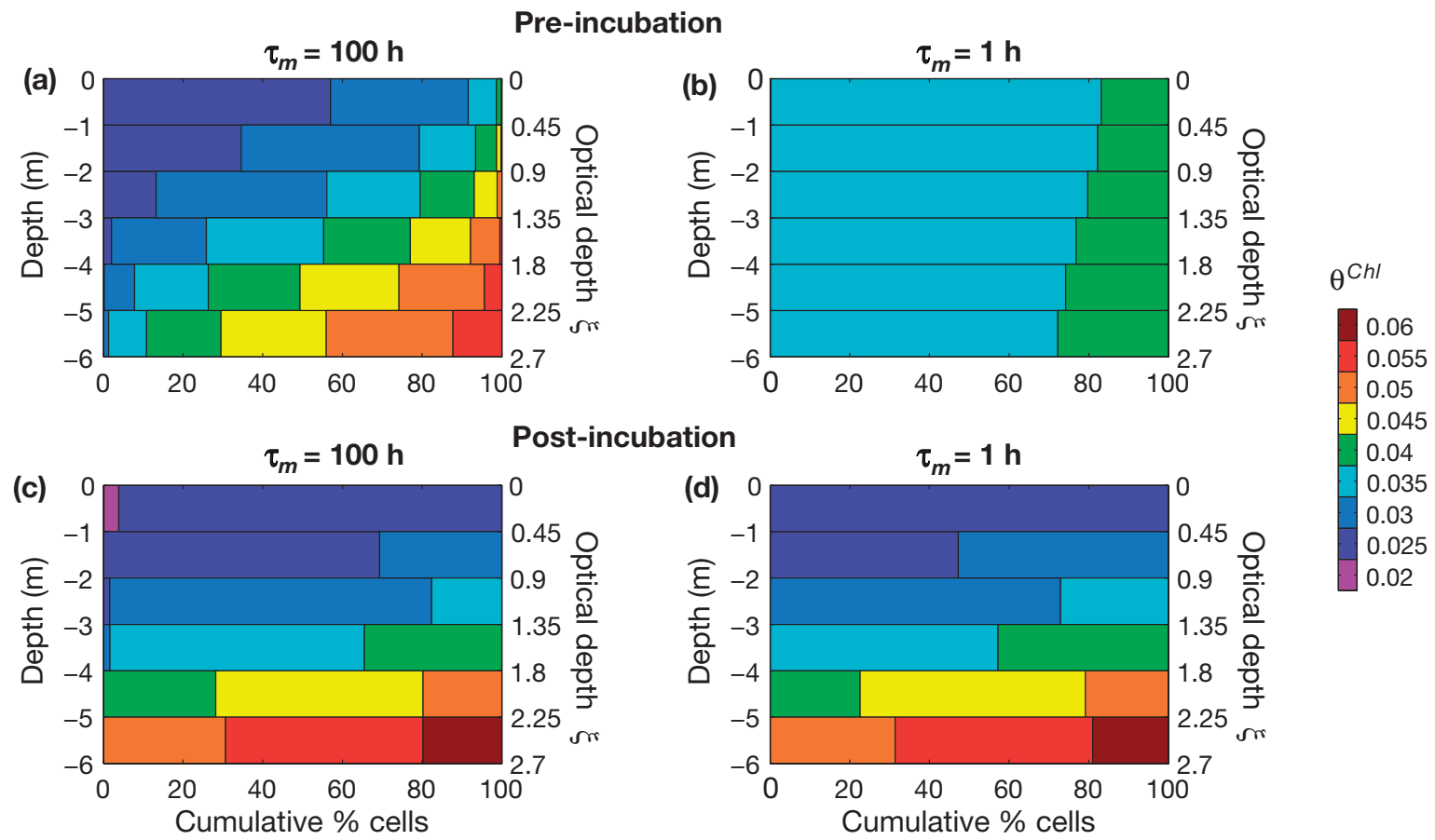

Fig. 3. Relative abundance of different Chl:C ratios, $\theta^{C h l}\left[\mathrm{gChl}(\mathrm{gC})^{-1}\right]$ for different depths in an optically shallow mixing layer $\left(\xi_{\mathrm{SML}}=2.7\right)$, using 2 different mixing time scales, $\tau_{m}$ (cf. Eq. 5). The presence of many colours at a particular depth indicates a great physiological heterogeneity of the phytoplankton population in terms of their Chl:C ratio, while differences in the colour distribution between the surface and bottom indicate vertical heterogeneity (due to insufficient mixing). (a,b) distribution at 17:30 h on the day prior to the $24 \mathrm{~h}$ incubation, i.e. where the cells are still allowed to move freely; (c,d) distribution at 17:30 h on the day of the $24 \mathrm{~h}$ incubation during which the cells had been kept at fixed depths 
the distribution of Chl:C ratios (Fig. 5). The same argument can be used to explain why $\varepsilon_{1}$ turns positive at greater depths where low light conditions lead to an increased $\mathrm{Chl}$ synthesis in combination with a reduced carbon uptake. For $\varepsilon_{2}$ we find the opposite trend, with $\mu_{C h l}^{\text {incub }}$ overestimating in situ growth $\left(\overline{\mu_{C}^{\text {mixed }}}\right)$ near the surface and underestimating it at depth. This is trivial, as it reflects the different light availabilities at different depths.

Although the errors at the individual depths can be considerable, reaching 50 to $100 \%$ (Fig. 4d), the differences between the SML-integrated growth rates $\bar{\mu}$ remain small (Table 2 ). Particularly for $\xi \gtrsim 4$, the in vitro growth rate, $\mu_{C h l}^{\text {incub }}$, significantly underestimates (a) $H=6 \mathrm{~m}, \tau_{m}=100 \mathrm{~h}, \xi_{\mathrm{SML}}=5.4$

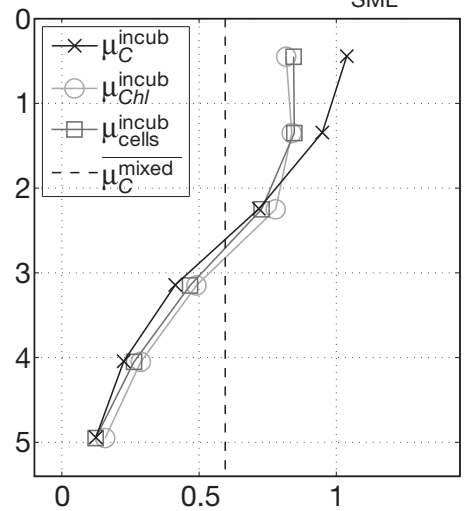

(e) $H=60 \mathrm{~m}, \tau_{m}=10000 \mathrm{~h}, \xi_{\mathrm{SML}}=5.4$

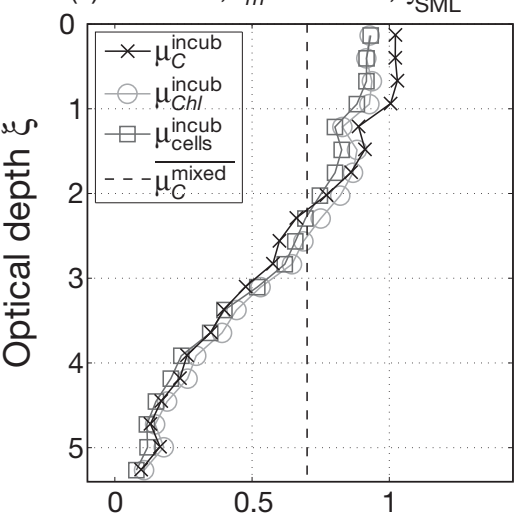

(i) as (a) but triple $k_{d}$ and $I_{m}=850 \mathrm{~W} \mathrm{~m}^{-2}$

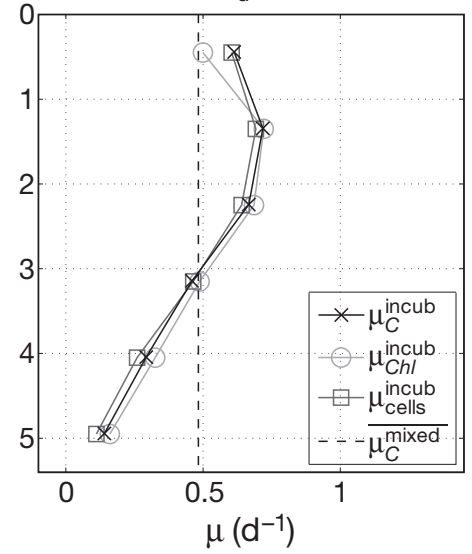

(b) Errors $\varepsilon_{1}$ and $\varepsilon_{2}$

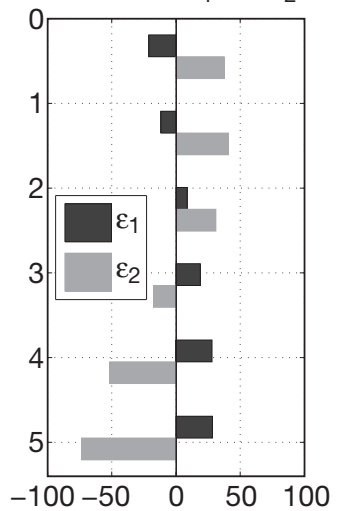

(f) Errors $\varepsilon_{1}$ and $\varepsilon_{2}$

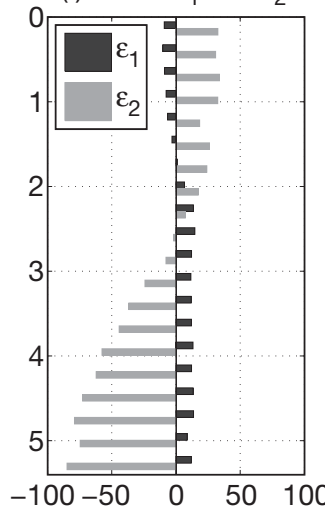

(j) Errors $\varepsilon_{1}$ and $\varepsilon$

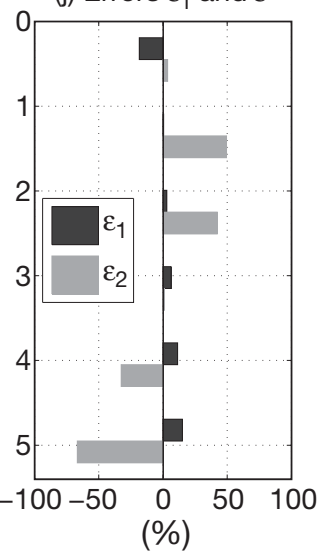

(c) $H=6 \mathrm{~m}, \tau_{m}=1 \mathrm{~h}, \xi_{\mathrm{SML}}=5.4$

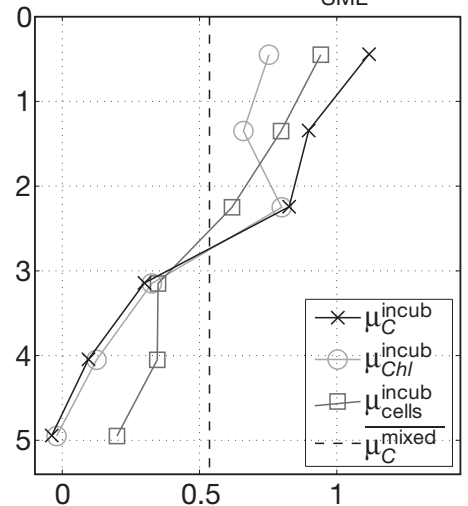

(g) $H=6 \mathrm{~m}, \tau_{m}=100 \mathrm{~h}, \xi_{\mathrm{SML}}=2.7$

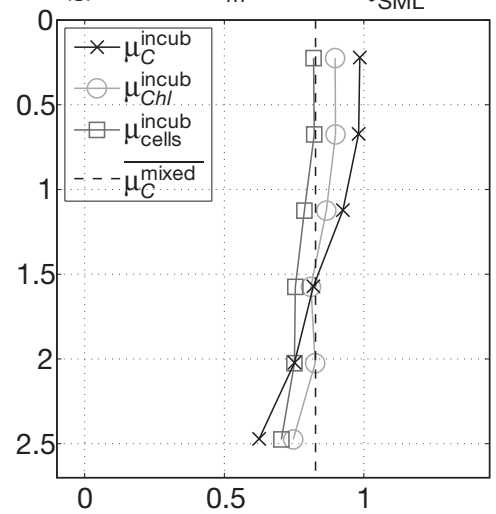

(h) Errors $\varepsilon_{1}$ and $\varepsilon_{2}$

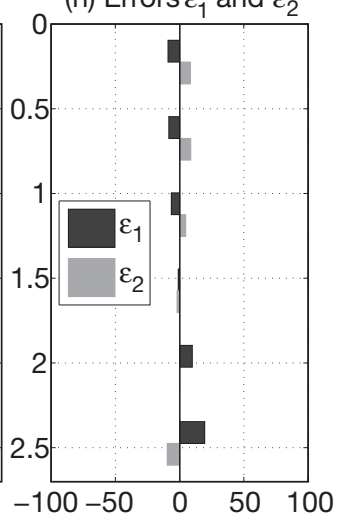

(k) as (c) but triple $k_{d}$ and $I_{m}=850 \mathrm{~W} \mathrm{~m}^{-2}$ (l) Errors $\varepsilon_{1}$ and $\varepsilon_{2}$

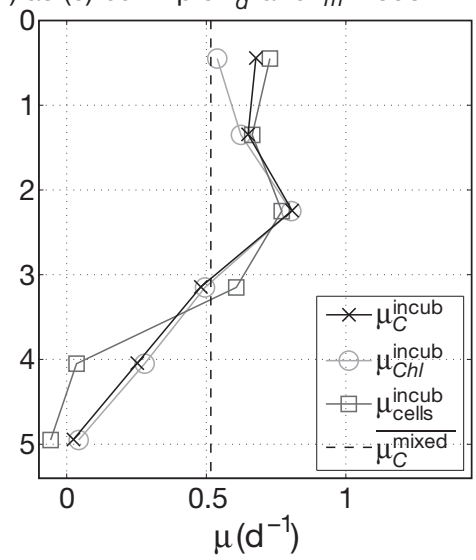

(d) Errors $\varepsilon_{1}$ and $\varepsilon_{2}$

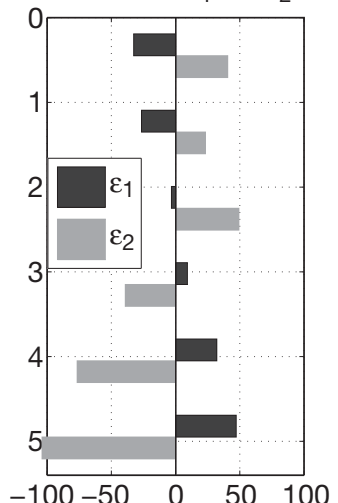




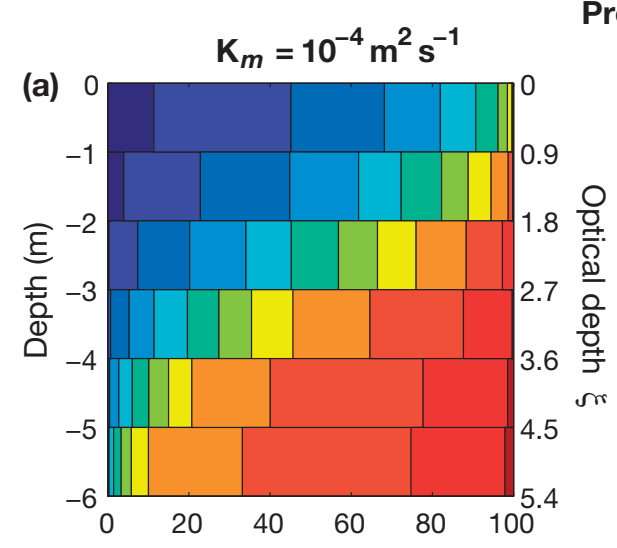

\section{Pre-incubation}
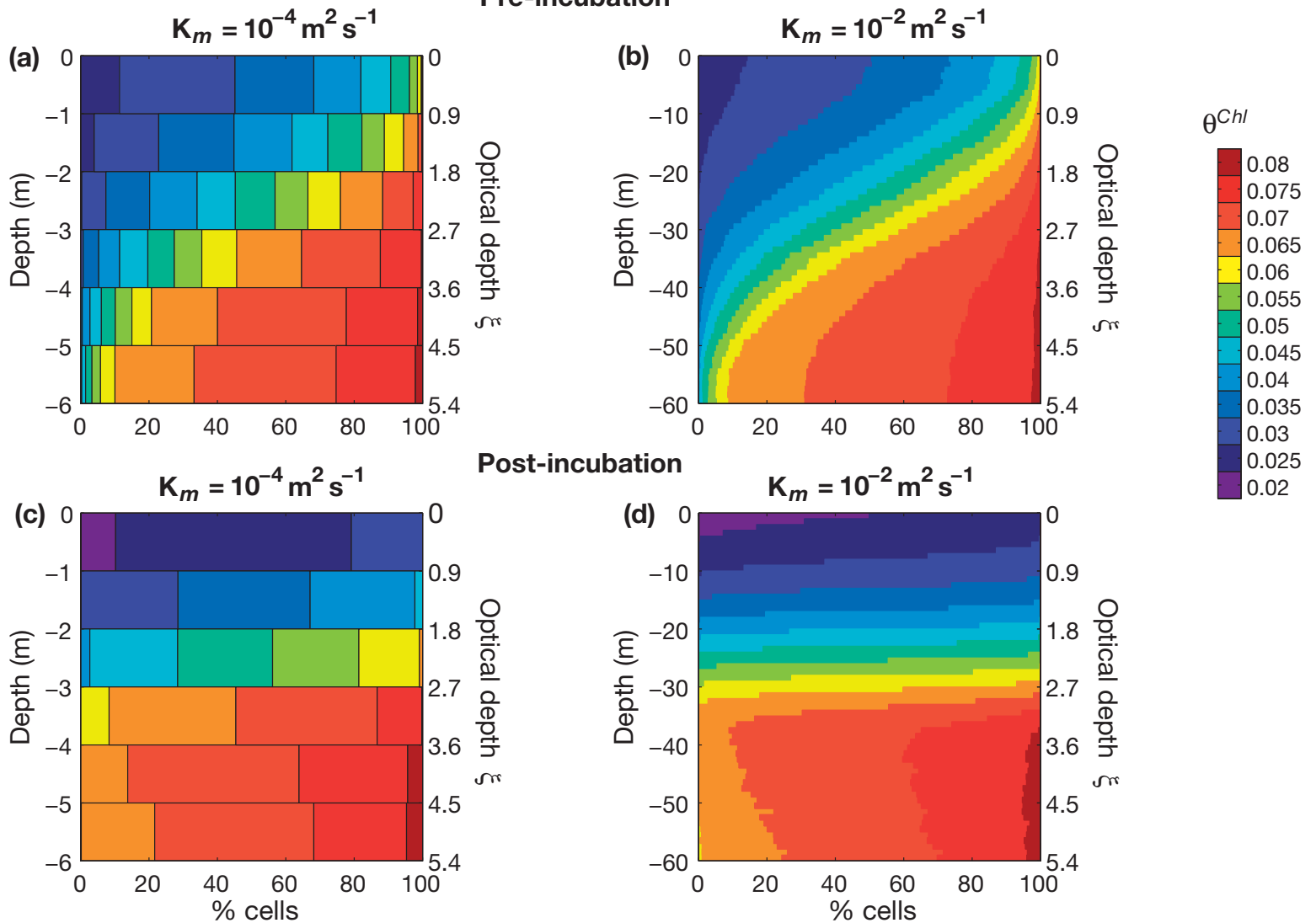

Fig. 5. Distributions of Chl:C for 2 different mixed layers which represent (a) a coastal setting (from Fig. 4a) and (b) an open ocean setting (cf. Fig. 3 for explanation of the colours and bars). The vertical resolution in (a) and (c) is $1 \mathrm{~m}$ and in (b) and (d) it is $3 \mathrm{~m}$. Although both SMLs differ in depth, attenuation coefficient, and turbulent mixing intensity, they have the same values for the mixing time scale $\left(\tau_{m}=100 \mathrm{~h}\right)$ and optical depth $\left(\xi_{\mathrm{SML}}=5.4\right)$. As a result, both SMLs show equivalent distributions of Chl:C

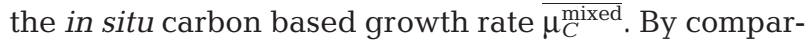
ing the different growth rates for a range of environmental scenarios (Fig. 4 ) we generally find that $\overline{\mu_{C}^{\text {mixed }}} \approx$ $\mu_{\text {Chl }}^{\text {mixed }}$ (Table 2).

For completeness, we also show the growth rate calculated from the increase in cell numbers, $\mu_{\text {cell }}$. In gen- eral, $\mu_{\text {cell }}(z)$ differs from the carbon-based equivalent, and also shows more variability in the vertical. Due to its dependence on the cell cycle it is a slightly coarser measure of growth rate, as the timing of cell division relative to the end of the incubation period could significantly alter the results. Nevertheless, the depth-

Table 2. Depth-averaged growth rates for the scenarios shown in Fig. 4 . The last 2 rows have triple $k_{d}$ and $I_{m}=850 \mathrm{~W} \mathrm{~m}^{-2} . \tau_{m}$ is in hours; units for the remaining environmental parameters can be found in Table 1

\begin{tabular}{|c|c|c|c|c|c|c|c|c|c|c|c|}
\hline \multirow[t]{2}{*}{ Fig. 4} & \multicolumn{5}{|c|}{ Environmental parameters } & \multicolumn{6}{|c|}{ Growth rates $\left(\mathrm{d}^{-1}\right)$} \\
\hline & $H$ & $K_{m}$ & $k$ & $\tau_{m}$ & $\xi_{\mathrm{SML}}$ & $\overline{\mu_{C h l}^{\text {incub }}}$ & $\overline{\mu_{C h l}^{\text {mixed }}}$ & $\overline{\mu_{C}^{\text {incub }}}$ & $\overline{\mu_{C}^{\text {mixed }}}$ & $\overline{\mu_{\text {cell }}^{\text {incub }}}$ & $\overline{\mu_{\text {cell }}^{\text {mixed }}}$ \\
\hline $\mathrm{a}$ & 6 & $10^{-4}$ & 0.9 & 100 & 5.4 & 0.62 & 0.60 & 0.68 & 0.59 & 0.61 & 0.60 \\
\hline $\mathrm{C}$ & 6 & $10^{-2}$ & 0.9 & 1 & 5.4 & 0.49 & 0.53 & 0.62 & 0.54 & 0.58 & 0.44 \\
\hline $\mathrm{e}$ & 60 & $10^{-4}$ & 0.09 & $10^{4}$ & 5.4 & 0.73 & 0.70 & 0.78 & 0.70 & 0.70 & 0.68 \\
\hline g & 6 & $10^{-4}$ & 0.45 & 100 & 2.7 & 0.84 & 0.83 & 0.86 & 0.83 & 0.77 & 0.78 \\
\hline \multicolumn{12}{|c|}{ Growth rates for a deep SML with same values of $\tau_{m}$ and $\xi_{\text {SML }}$ as in Fig. $4 \mathrm{a}$} \\
\hline- & 60 & $10^{-2}$ & 0.09 & 100 & 5.4 & 0.61 & 0.60 & 0.68 & 0.59 & 0.61 & 0.60 \\
\hline \multicolumn{12}{|c|}{ Using triple $k_{d}$ and $I_{m}=850 \mathrm{~W} \mathrm{~m}^{-2}$} \\
\hline $\mathrm{i}$ & 6 & $10^{-4}$ & 0.9 & 100 & 5.4 & 0.51 & 0.48 & 0.51 & 0.48 & 0.50 & 0.48 \\
\hline $\mathrm{k}$ & 6 & $10^{-2}$ & 0.9 & 1 & 5.4 & 0.49 & 0.52 & 0.52 & 0.52 & 0.51 & 0.69 \\
\hline
\end{tabular}


integrated rates typically give an acceptable approximation of the in situ values (Table 2).

\section{Sensitivity to optical depth and mixing time scale}

A reduction in the mixing time scale $\tau_{m}$ produces a more homogeneous water column (Figs. 3b \& 6b), which in turn amplifies the differences between the freely mixing and static incubation, yielding slightly larger errors $\varepsilon_{1}$ and $\varepsilon_{2}$. An increase in the mixing time scale, on the other hand, means that the cells have a higher residence time at each depth, which allows them to adapt better to the ambient light level. In such a low turbulence scenario, arresting the cells in place during the fixed-depth bottle incubation thus represents only a small change to the freely mixing conditions (compare the mixed and incubated conditions in Fig. $6 \mathrm{c}$ ) and the error $\varepsilon_{1}$ is reduced (Fig. 4 e,f). However,
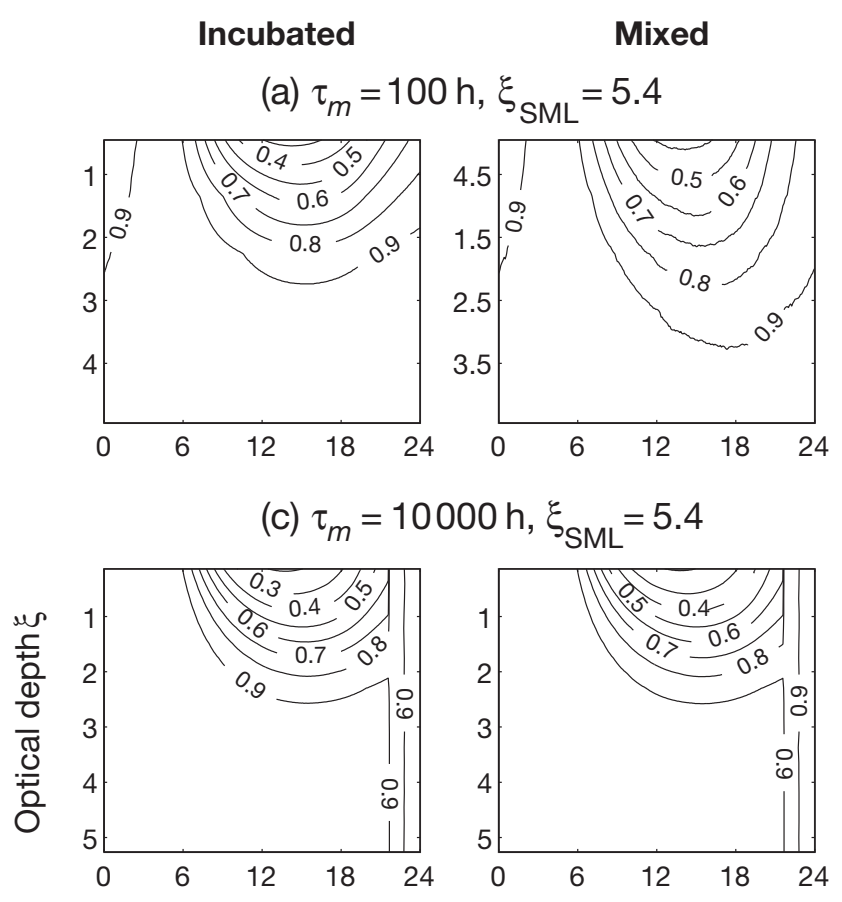

(e) as in (a) but triple $\mathrm{k}_{d}, \mathrm{I}_{m}=850 \mathrm{~W} \mathrm{~m}^{-2}$
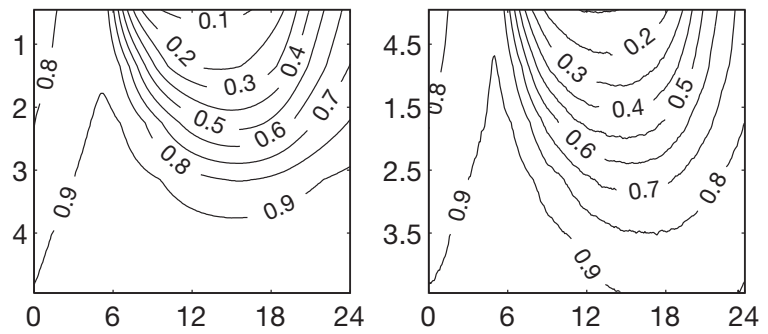

$\varepsilon_{2}$ remains large, which is to be expected given the vertical heterogeneity in $\mu_{C h l}^{\text {incub }}$. The fact that the cells are better adapted to their light environment and thus less inhibited at greater depths (Fig. 6c vs b) also results in higher depth-integrated growth rates $\left(\mu_{\mathrm{Chl}}^{\mathrm{mixed}}\right.$ and $\overline{\mu_{C}^{\text {mixed }}}$, which reach $0.7 \mathrm{~d}^{-1}$ for $\tau_{m}=10^{4} \mathrm{~h}$, compared to $0.6 \mathrm{~d}^{-1}$ for $\tau_{m}=100 \mathrm{~h}$, and 0.54 for $\tau_{m}=1 \mathrm{~h}$ (Table 2). With everything else left unchanged, a reduction in turbulence thus results in a water column that is more productive.

If we use the same mixing time scale as in Fig. 4(a) but halve the attenuation coefficient, thereby halving $\xi_{\mathrm{SML}}$, the result is a significant reduction in the errors, in particular, $\varepsilon_{2}$ (Fig. $4 \mathrm{~g}, \mathrm{~h}$ ). Having made the SML more transparent to light means that the base of the SML receives relatively high light intensities (the location of the $1 \%$ light level for the simulations in Fig. $4(\mathrm{a}-\mathrm{f})$ is now the location of the $10 \%$ light level). The weaker light gradient produces a weaker vertical gradient in

Incubated

(b) $\tau_{m}=1 \mathrm{~h}$

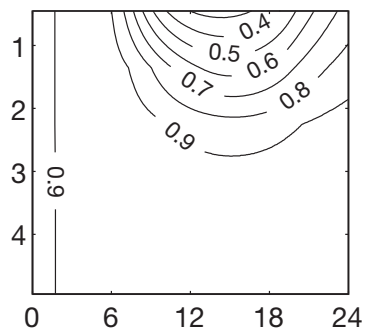

$\xi_{\mathrm{SML}}=5.4$

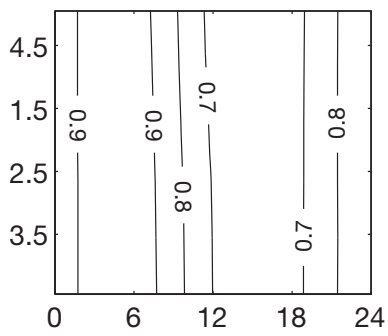

(d) $\tau_{m}=100 \mathrm{~h}, \xi_{\mathrm{SML}}=2.7$
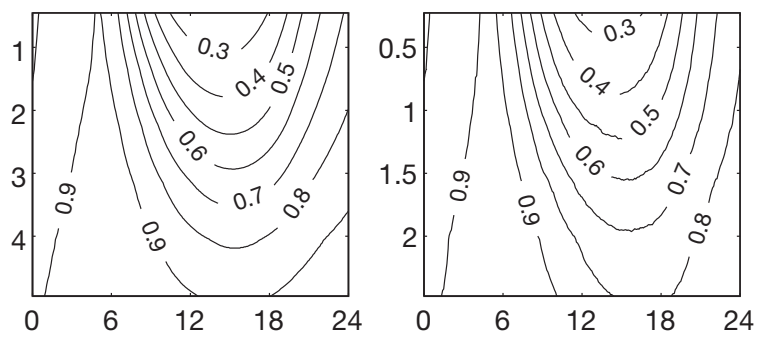

(f) as in (b) but triple $\mathrm{k}_{d}, \mathrm{I}_{m}=850 \mathrm{~W} \mathrm{~m}^{-2}$
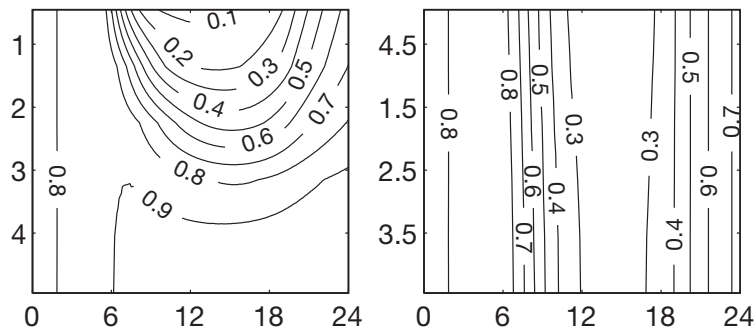

Time of day (h)

Fig. 6. Value of the photoinhibition parameter $\vartheta$ for the simulations from Fig. 4 
Chl:C and a smaller heterogeneity within a particular depth bin (cf. Fig. 3a). As a result, although the error $\varepsilon_{1}$ is still of the order of $\mathrm{O}(20-30 \%)$, the more important $\varepsilon_{2}$ has almost disappeared, which means that $\mu_{C h l}^{\text {incub }}$ is now a much better approximation of the in situ growth rate $\overline{\mu_{C}^{\text {mixed }}}$, irrespective of the depth at which the incubation takes place. Despite photoinhibition extending to the base of the SML (Fig. 6d), the high light availability throughout the SML results in higher overall growth rates (Table 2).

The results in Fig. 4(a,b) were obtained for a shallow $(H=6 \mathrm{~m})$ and relatively turbid $\left(k=0.9 \mathrm{~m}^{-1}\right) \mathrm{SML}$ representative of an estuary or coastal lagoon. The optical depth of this SML was $\xi_{\mathrm{SML}}=5.4$ and the mixing time scale $\tau_{m}=100 \mathrm{~h}$ (Eq. 5), which renders the water column vertically heterogeneous, both in terms of Chl:C (Fig. 5a) and also the inhibition $\vartheta$ (Fig. 6a). We found that experiments with identical values of $\xi_{\mathrm{SML}}$ and $\tau_{m}$ delivered the same trends and magnitudes in the vertical Chl:C distribution, the resulting growth rates and associated errors. E.g. moving from the estuarine setting in Fig. $4(a, b)$ to an open ocean setting with $H=60 \mathrm{~m}$, the same values for $\xi_{\mathrm{SML}}$ and $\tau_{m}$ can be maintained by reducing the PAR attenuation to $k=0.09 \mathrm{~m}^{-1}$ and increasing the eddy diffusivity to $K_{m}=10^{-2} \mathrm{~m}^{2} \mathrm{~s}^{-1}$ (see Table 2). The result is an identical distribution of Chl:C (Fig. 5) and also identical distributions and magnitudes for the growth rates and associated errors (not shown). Compared to the diagrams in Fig. 3, the cells achieve higher values of Chl:C in Fig. 5, as the water column was more turbid in this experiment and thus the lower part of the SML was more light limited.

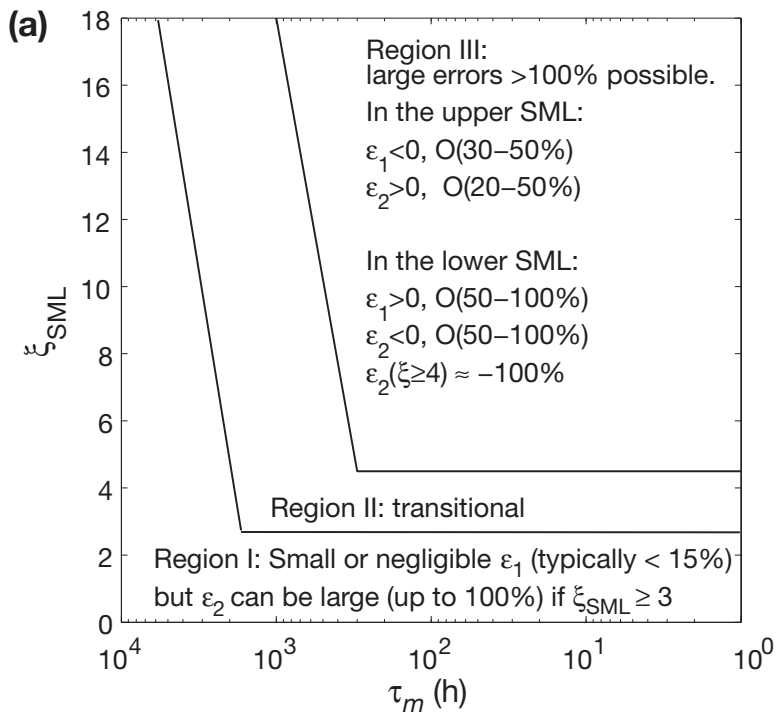

\section{Photoinhibition}

The simulations in Fig. 4a-h used a moderate value for the photodamage probability, $k_{d}$, which yields minimum values for $\vartheta$ of about 0.4 in a freely mixing water column with $\tau_{m}=100 \mathrm{~h}$ (Fig. 6a). The amount of inhibition generally decreases with increasing turbulence (Fig. 6a,b) but extends deeper into the SML. In an effort to maximise the photodamage, we repeated the simulations from Fig. 4a,c with a 3 times higher damage probability $k_{d}$ and an increased noon irradiance $I_{m}$. The result is a higher photoinhibition (Fig. 6e,f) which leads to a depression in the incubated growth rates $\mu_{C}^{\text {incub }}(F i g .4 i, k)$. In the freely mixing water column, the effect on $\mu_{C}^{\text {mixed }}$ is only noticeable in a moderately turbulent water column (Fig. 4a,i) while in a highly turbulent water column, $\overline{\mu_{C}^{\text {mixed }}}$ is almost unaffected (Fig. 4c,k). Because the carbon based growth rate is more affected by the higher inhibition and due to the lower depth-averaged growth rates, both $\varepsilon_{1}$ and $\varepsilon_{2}$ are reduced near the surface and at depth except where the growth rate becomes negative (Fig. $4 \mathrm{j}, 1)$.

To generalise our findings, we repeated the above experiments for a wide range of physical environments and found that the vertical distribution and magnitude of errors depends on the 2 parameters $\xi_{\mathrm{SML}}$ and $\tau_{m}$ (Fig. 7a). $\varepsilon_{1}$ and $\varepsilon_{2}$ were generally small if the SML was well lit, i.e. $\xi_{\text {SML }} \lesssim 3$. In these cases $\mu_{C h l}^{\text {incub }}$ delivered a good approximation of the growth in the freely mixing water column $\overline{\mu_{C}^{\text {mixed }}} . \varepsilon_{1}$ was also small if the water column was very stable with low turbulence intensities ( $\tau_{m}$ is very large) (Region I in Fig. $7 a$ ). For $\xi \gtrsim 4$, we found that $\varepsilon_{2} \approx-100 \%$ irrespective of $\tau_{m}$. As the SML

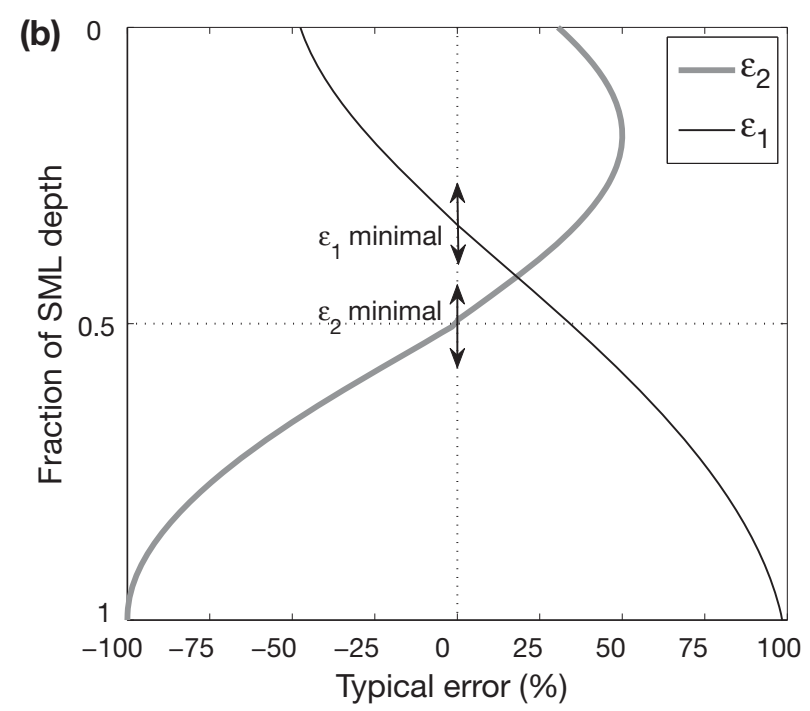

Fig. 7. Summary of the general trends observed in the numerical experiments. The double-ended arrows in (b) indicate the ranges where the respective errors are minimal. If $\xi_{\mathrm{SML}} \lesssim 6, \varepsilon_{2}$ is minimal near the mid-SML and $\varepsilon_{1}$ slightly above. For more turbid mixing layers these locations are shifted upward 
becomes more turbid and also more turbulent (Region III in Fig. 7a) both errors can become very large. Near the surface $\mu_{C h l}^{\text {incub }}$ typically underestimates the carbon equivalent $\mu_{C}^{\text {incub }}$ (unless the inhibition is very high) while overestimating the in situ growth rate $\overline{\mu_{C}^{\text {mixed }}}$ by 10 to $50 \%$, depending on the environmental conditions. $\varepsilon_{1}$ is therefore typically negative near the surface while $\varepsilon_{2}$ is positive (Fig. 7b). The opposite is true for the lower SML, where the signs of $\varepsilon_{1}$ and $\varepsilon_{2}$ change and the magnitudes approximately double. The region where we found the errors to be the smallest is near the midSML (as long as $\xi_{\text {mid-SML }} \lesssim 4$ ).

\section{Sensitivity to the incubation time}

The results shown in Fig. 4 \& Table 2 were obtained for an incubation time of $24 \mathrm{~h}$ extending from midnight till midnight on the last day of the simulations. One might intuitively assume that errors could be reduced by shortening the incubation time, i.e. the difference to the in situ conditions would be smaller if the cells were only stranded at fixed depths for a few hours rather than the entire day. We found that the opposite holds true, at least for low to moderate levels of inhibition. If the bottles are incubated for only $4 \mathrm{~h}$ from 10:00 to 14:00 $\mathrm{h}$ for instance (cf. Marra 1978), both the sign and magnitude of the errors change significantly (Fig. 8a-d). Compared to the $24 \mathrm{~h}$ incubations, the depth averaged Chl-based in vitro growth rate $\overline{\mu_{\text {Chl }}^{\text {incub }}}$ is now only about half the in situ value $\overline{\mu_{C}^{\text {mixed }}}$. By shortening the incubation time, and carrying out the incubation symmetrically around noon, we have biased our measurements because the time of maximal irradiance is also the time of maximal carbon uptake, while the Chl:C ratio generally remains low. As a consequence, $\mu_{C h l}^{\text {incub }}$ significantly underestimates $\overline{\mu_{C}^{\text {mixed }}}$ throughout the water column. While $\varepsilon_{1}$ maintains a similar distribution (negative near the surface and positive at depth), the more important $\varepsilon_{2}$ has turned negative throughout the water column. If we induce a higher photoinhibition in the cells by tripling the damage probability $k_{d}$ and raising the noon irradiance to $I_{m}=850 \mathrm{~W} \mathrm{~m}^{-2}$ (Fig. $8 \mathrm{e}-\mathrm{h}$ ), the errors are reduced and $\mu_{C h l}^{\text {incub }}$ now provides a good estimate of $\overline{\mu_{C}^{\text {mixed }}}$ in mid SML $\left(\varepsilon_{2}\right.$ is very small there). However, $\mu_{C h l}^{\text {incub }}$ still underestimates its carbon equivalent by 10 to $15 \%$. (a) $H=6 \mathrm{~m}, \tau_{m}=100 \mathrm{~h}, \xi_{\mathrm{SML}}=5.4$

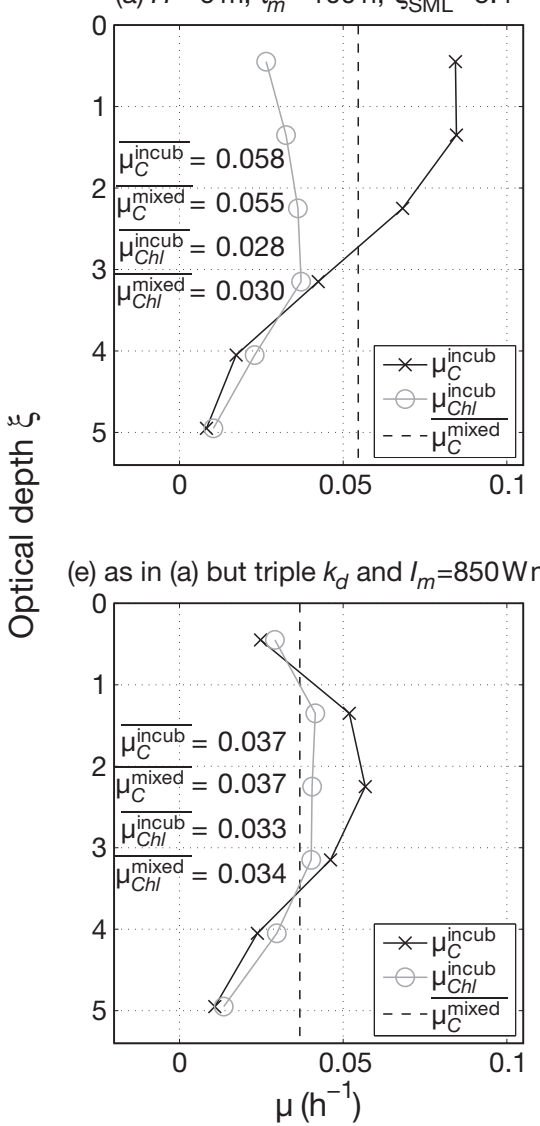

(b) Errors $\varepsilon_{1}$ and $\varepsilon_{2}$

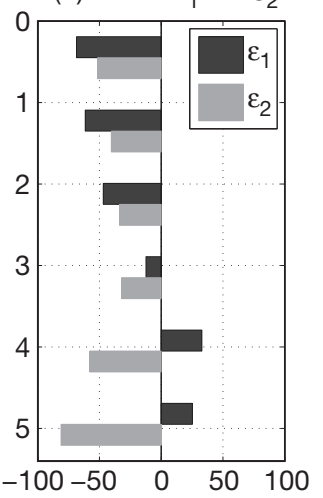

(c) $H=6 \mathrm{~m}, \tau_{m}=1 \mathrm{~h}, \xi_{\mathrm{SML}} 5.4$

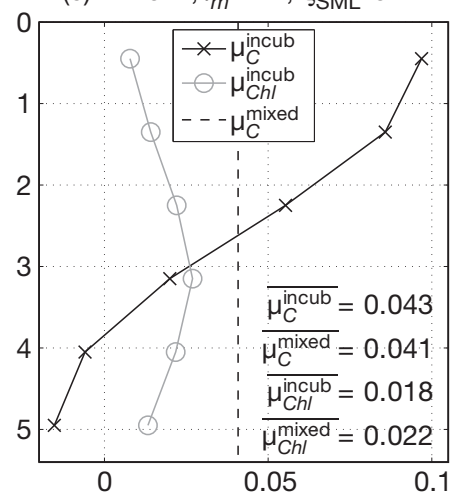

(d) Errors $\varepsilon_{1}$ and $\varepsilon_{2}$

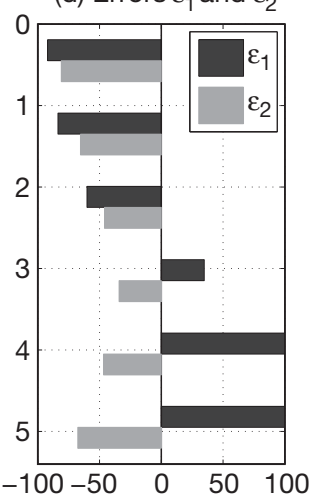

(g) as in (c) but triple $k_{d}$ and $I_{m}=850 \mathrm{Wm}^{-2}$ (h) Errors $\varepsilon_{1}$ and $\varepsilon_{2}$ (f) Errors $\varepsilon_{1}$ and $\varepsilon_{2}$
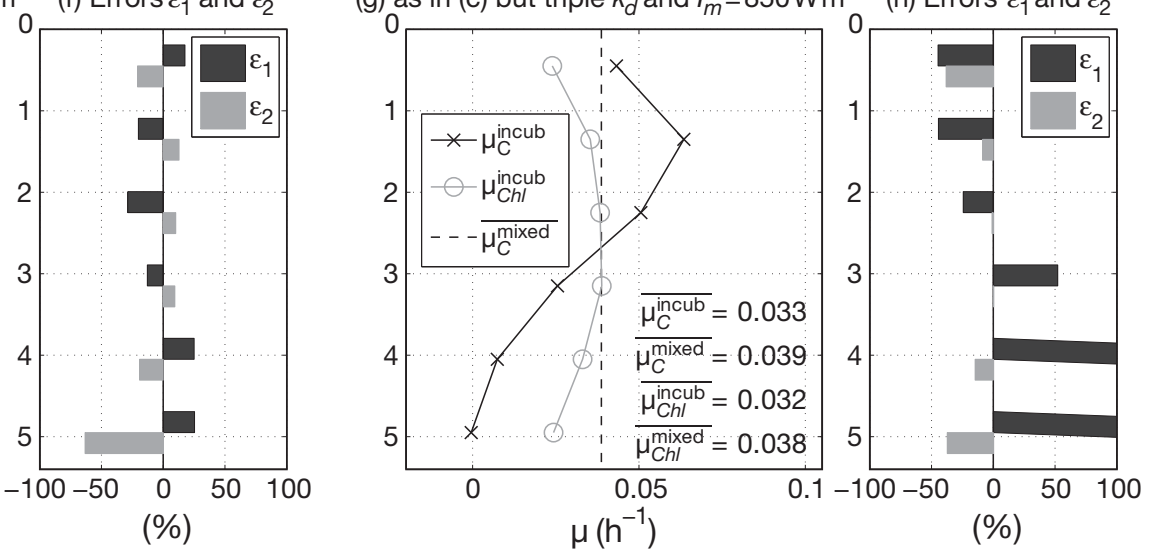

Fig. 8. Corresponding results to panels $(\mathrm{a}-\mathrm{d})$ and (i-l) in Fig. 4, except that the incubation time was not $24 \mathrm{~h}$ but only $4 \mathrm{~h}$ from 10:00 to 14:00 h. The cell-based growth rate is not very meaningful for such short incubation times and has therefore been omitted from this plot 
(a) $H=6 \mathrm{~m}, \tau_{m}=1 \mathrm{~h}, \xi_{\mathrm{SML}}=5.4$

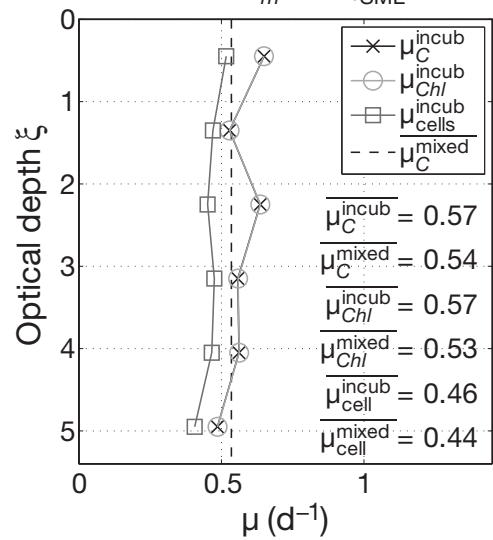

(b) Errors $\varepsilon_{1}$ and $\varepsilon_{2}$

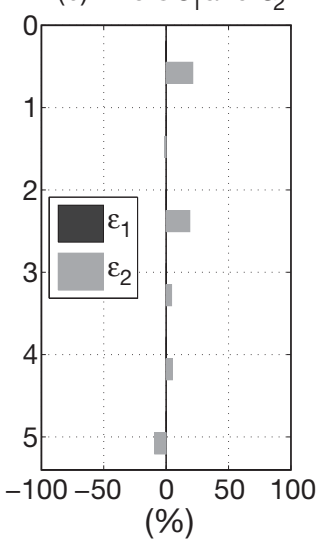

Fig. 9. Applying the yo-yo-approach to the scenario from Fig. 4c. Instead of incubating bottles at fixed depths, they were cycled vertically through the SML using $w_{\text {yo-yo }}=4.6 \mathrm{~m} \mathrm{~h}^{-1}$ (cf. Eq. 14)

\section{Yo-yo techniques}

To test whether a yo-yo approach, in which the incubation bottles are vertically moved up and down through the water column, could reduce the associated errors, we applied this approach to the scenario from Fig. 4c, which falls into Region III in Fig. 7a and therefore delivers relatively large errors. The result is a dramatic reduction in both types of errors (Fig. 9). By oscillating the sampling bottles up and down we were able to maintain them in balanced growth and obtain fairly accurate estimates of the growth rate in the freely mixing water column.

In order to effectively reduce the errors, it is crucial to choose an appropriate value for the oscillation velocity $w_{\text {yo-yo }}$. If the mixing time scale is low (in Fig. $9 \tau_{m}=$ $1 \mathrm{~h}$ ) an overestimation of $w_{\text {yo-yo }}$ is not too critical as the high turbulence renders the SML fairly homogeneous (Figs. 3b \& 6b). However, an underestimation of $w_{\text {yo-yo }}$ can produce significant errors (not shown).

\section{DISCUSSION}

Accurate estimates of phytoplankton in situ growth rates are important for many applications, ranging from global climate predictions to local management of water quality. Using a modelling approach we explored the magnitude of potential errors associated with the commonly used fixed-depth bottle incubation method. While there are many different sources of error associated with fixed-depth bottle incubations (e.g. Furnas 2002), we focused our efforts on the quantification of 2 particular types of errors:

(1) The first error $\left(\varepsilon_{1}\right)$ accounts for the difference between the commonly used Chl-derived growth rate
$\mu_{C h l}^{\text {incub }}(z)$ and its carbon-derived equivalent $\mu_{C}^{\text {incub }}(z)$. The discrepancy is related to the fact that the cells continuously photoacclimate and are typically not in balanced growth.

(2) The second error $\left(\varepsilon_{2}\right)$ accounts for the effect of keeping the incubations at fixed depths (in stable light conditions) and assuming that the obtained growth rate corresponds to the entire mixing layer, i.e. it describes the discrepancy between $\overline{\mu_{C h l}^{\text {incub }}(z)}$ and the depth integrated growth rate achieved in the freely mixing water column, $\overline{\mu_{C}^{\text {mixed }}}$ which, for the purposes of this study, we considered to be the 'true' in situ growth rate.

We showed that depending on the depth at which the incubation takes place, both errors can be of the same order of magnitude as the growth rate itself. Some methods exist which can help alleviate (Gutiérrez-Rodríguez et al. 2010) or even completely avoid (Calbet \& Landry 2004) $\varepsilon_{1}$, but they cannot remedy the potentially more important $\varepsilon_{2}$. Even if we reduce $\varepsilon_{1}$ completely, there is still a considerable error between $\mu_{C}^{\text {incub }}$ and $\overline{\mu_{C}^{\text {mixed }}}$ (Fig. 4). $\varepsilon_{2}$ can be reduced by either oscillating the bottle through the SML (Fig. 9) or by using more than one depth for the incubation (Table 2).

Our results have shown that both $\varepsilon_{1}$ and $\varepsilon_{2}$ can be rather large for a wide range of environmental conditions. In all tested scenarios (including the highly turbulent ones), the best depth to carry out the fixeddepth incubation (using only a single depth) was near the centre of the SML, if-and only if - the optical depth of the mid-SML, $\xi_{\text {mid-SML, }}$ is no larger than 4 . If $\xi_{\text {mid-SML }}>4$ the incubation should be carried out near $\xi=3.5$ to 4 . If most of the SML lies within the euphotic zone, and if the turbulence is low to moderate (i.e. if the physiology throughout the SML is vertically heterogeneous, $\tau_{m} \geq 100 \mathrm{~h}$ ) we found that a good approach to reduce the errors is to carry out the incubation experiment not only at a single depth but at a series of depths throughout the SML and then calculate the growth rate from this depth integrated increase in Chl, which yields good agreement between $\overline{\mu_{C}^{\text {mixed }}}$ and $\overline{\mu_{C h l}^{\text {incub }}}$ (Fig. 4 \& Table 2). Our results were quite insensitive to small changes in the growth or photoacclimation parameters used in the model. Only for very high photodamage probabilities $\left(k_{d}\right)$ can the errors $\varepsilon_{1}$ and $\varepsilon_{2}$ be reduced near the surface, as uptake of carbon is suppressed due to lower photosynthetic efficiencies and $\varepsilon_{2}$ can change sign (Fig. 4i-1). For the range of parameter values we tested, we did not find any significant effect on $\varepsilon_{2}$ at greater depths, however.

If the SML is more turbulent (e.g. if the distribution of Chl:C ratios is fairly constant with depth, $\tau_{m} \leq 10 \mathrm{~h}$ ), $\mu_{\text {Chl }}^{\text {incub }}$ can significantly differ from $\overline{\mu_{C}^{\text {mixed }}}$ (Fig. 4c,d) and a superior approach to reduce $\varepsilon_{2}$ is to oscillate the incubation bottle through the layer (Fig. 9). Although our 
modelling approach showed that this yo-yo method delivers far smaller errors, the problem remains that we have no reliable method of estimating the oscillation velocity, the vertical amplitude, or the time course of the oscillations (e.g. linear velocity vs. sinusoidal vs. a more random movement). Eq. (14) represents an empirical relationship which produced results that were quantitatively in good agreement with those obtained in normally mixed conditions but it requires prior knowledge of the turbulence diffusivity in the water column, which is often unknown. A wrong choice may not increase accuracy.

In general, the conclusions are:

(1) The magnitude of $\varepsilon_{1}$ decreases with increasing mixing time scale $\tau_{m}$ (Eq. 5) (Fig. 7a).

(2) The magnitude of both errors increases with increasing turbidity of the water column ( $\xi_{\mathrm{SML}}$, Eq. 5) (Fig. 7a).

(3) If the mixing layer is optically shallow and relatively stable (low turbulence), then fixed-depth incubations at optical depths $\lesssim 4$ should yield good estimates (errors $\lesssim 20 \%$ ) of the growth rate in the freely mixing water column (Fig. 7).

(4) If the water column is more turbid and/or more turbulent, the best region to use fixed-depth bottle incubations (error $\lesssim 30 \%$ ) is near the centre of the surface mixing layer, provided that this region has an optical depth of $\lesssim 4$ (Fig. 7b).

(5) Reducing the incubation time from 24 to $4 \mathrm{~h}$ does not necessarily lead to improved accuracy. For low to moderate photoinhibition, a shorter incubation time, especially if located symmetrically about noon, will lead to a significant increase in the associated errors, in particular $\varepsilon_{2}$ (Fig. 8).

(6) One additional way to reduce the errors in highly turbulent and turbid mixing layers is to vertically oscillate the incubation bottles through the water column (yo-yo-method) which, by choosing an appropriate yoyo velocity and amplitude, can reduce the errors to $\lesssim$ $15 \%$ throughout the water column (Fig. 9b).

(7) We often found that $\overline{\mu_{C h l}^{\text {incub }}} \approx \overline{\mu_{C}^{\text {mixed }}}$ (Fig. 4). Although we are aware that logistic constraints often do not permit this, we found that the best way to reduce $\varepsilon_{2}$ to negligible levels is to carry out the incubation experiments at several depths which cover the different light environments within the mixing layer.

\section{Accuracy of yo-yo incubations}

The yo-yo method was a viable alternative only if the water column was turbulent enough so that the cells showed a fairly homogeneous physiology throughout the layer, and most of the mixing layer was within the euphotic zone. If the layer is not very turbulent, the success of this method is very sensitive to the choice of the depth at which the sample is taken and at which the oscillation is started. E.g. if we were to use the yo-yo method in a shallow $(H=6 \mathrm{~m})$ and turbid $(k=$ $0.9 \mathrm{~m}^{-1}$ ) water column with an eddy diffusivity of $10^{-4} \mathrm{~m}^{2} \mathrm{~s}^{-1}$ (i.e. $w_{\text {yo-yo }}=0.46 \mathrm{~m} \mathrm{~h}^{-1}$ ) and if we start the incubation at midnight, then cells that were originally near the surface would already be at an optical depth of about 1.5 by the time the sun rises. By noon the centre of the depth bin that was initially at the surface would be at the base of the SML and only by the time the sun was setting would the cells have returned to the surface. Hence in such a scenario the cells that started near the surface would have spent much of the daylight hours at great optical depths where the light availability is low (and vice versa for cells that start at greater depths). If we start the yo-yo incubation at sunrise or noon, instead of midnight, the effect on the cells is quite different, hence the high sensitivity of the results to the timing of the incubation. Since the error associated with fixed-depth incubations in water columns that are optically shallow is quite low (Fig. $4 \mathrm{~g}, \mathrm{~h}$ ), one could argue that in such environments it is not necessary to use the yo-yo technique as the fixed-depth incubations might already yield sufficiently accurate results. Even if the water column is slightly more turbid, it may be worthwhile considering whether the additional effort of installing an oscillation mechanism might not be better spent on suspending a series of bottles at different depths that are representative of the entire SML and which may deliver superior results $\left(\overline{\mu_{C}^{\text {mixed }}} \approx \overline{\mu_{C h l}^{\text {incub }}}\right)$ without the added complication of having to choose the parameters for the yo-yo oscillation.

All our results regarding the yo-yo technique should be considered as preliminary. With our implementation of the method, we were able to show that oscillating the incubation bottles can have a positive effect in certain situations, but not in all. Further investigations into the yo-yo technique are necessary, however, so that more detailed and quantitatively more sound recommendations for an adequate sampling protocol can be made.

\section{Turbulence parameterisation}

In the present study we chose a rather simple parameterisation of turbulence, namely the eddy diffusivity approach. As an additional simplification we decided to prescribe the diffusivity profiles using analytical equations (Eq. 4) rather than obtaining the values from a $k-\varepsilon$ model that calculates the diffusivity dynamically from the external forcing and ambient water column stability (e.g. Ross \& Sharples 2007). As a result, our 
diffusivity profiles are fairly constant throughout the SML (Fig. 1) and do not change with time. The discrete output of eddy diffusivities obtained from a $k-\varepsilon$ model does not fulfill the necessary criteria for use with the random walk equation (Eq. 2). As a result, the discrete data need to be smoothed (e.g. using cubic splines) in order to achieve the necessary continuity and differentiability in the profiles (Ross \& Sharples 2004). As the diffusivity gradients are typically large near the SML boundaries, the number of nodes for the spline also needs to be quite large, yielding a high number of coefficients to evaluate a large number of polynomials for just 1 single profile which would change every 1 to $2 \mathrm{~min}$. In tests with several such profiles we found that the most important aspects of the diffusivity profile that need to be captured are the gradients (towards the surface and bottom) and the mid-SML amplitude. Any other structure in the profiles is redundant, as it does not have any significant effect on the biology. The overall results presented in this study were thus not affected by the simplified shape of the diffusivity profiles used.

We also tested the effect of a time-varying diffusivity by examining 2 different scenarios: (1) a scenario where the mixing is dominated by periodic (M2) tidal turbulence, as would be the case in an estuary or shelf sea, and where the diffusivity varied between $K_{m}$ (during the ebb and flood flows) and $10 \%$ of $K_{m}$ (during the high and low water stand) (see for instance the bottom mixed layer in Fig. 3c of Ross \& Sharples 2007), and (2) a scenario where the intermittency was largely due to changes in the surface wind forcing and where the diffusivity varied randomly between $K_{m}$ and $1 \%$ of $K_{m}$. In both cases the impact on the errors was minimal and did not warrant the inclusion of such effects in our analysis.

A third simplification in our experiments was that the SML depth was kept constant during the $5 \mathrm{~d}$ experiments and did not show any periodic deepening at night, even for the scenarios where we used convective overturning (cf. Woods \& Onken 1982, Barkmann \& Woods 1996). We therefore tested a scenario in which the SML depth oscillated between $-75 \mathrm{~m}$ and $-45 \mathrm{~m}$ (deepening at night associated with an increase in $K_{m}$ and shallowing during the day) with the $1 \%$ light level being at about $-51 \mathrm{~m}$, and found that the overall effect was a slight increase in $\varepsilon_{2}$ in the top half of the SML $[O(20 \%)]$ but no significant effect on $\varepsilon_{1}$ or on either error in the lower SML. We therefore expect our results to hold up also in a more dynamic physical setup.

While our results are obviously affected not only by our treatment of turbulence, but also by our somewhat idealised (and therefore tractable) treatment of both photoacclimation and photoinhibition, it is neverthe- less the first study of its kind to employ a relatively sophisticated individual based model, both for the physics and the biology, to address some of the problems associated with fixed-depth bottle incubations. Due to our inability to measure in situ growth rates non-intrusively in the real world, it could be argued that a model is in fact the only viable approach available to us at present in order to undertake such a comparison. One of the challenges facing both modellers and experimentalists is the possibility of interactions between the processes that have different characteristic time scales, so that a more fully integrated model may need to be developed.

Acknowledgements. This study received funding from the European Union Seventh Framework Programme (FP7/2007-2013) Marie Curie Intra-European Fellowship for Career Development under grant agreement no. 255396 for project AQUALIGHT (www.aqualight.info). R.J.G.'s research on photoacclimation is supported by the UK Natural Environment Research Council (NE/G003688/1). M.L.A. benefited from a FPU doctoral scholarship from the Spanish Ministry of Science and Innovation (MICINN). The authors also acknowledge financial support from the Spanish funded projects SUMMER (CTM2008-03309/MAR), ANERIS (PIF08-015), and ECOALFACS (CTM2009-09581; a project endorsed by the 'Harmful Algal Blooms in Stratified Systems' CRP of the GEOHAB programme).

\section{LITERATURE CITED}

Anning T, MacIntyre HL, Pratt SM, Sammes PJ, Gibb S, Geider RJ (2000) Photoacclimation in the marine diatom Skeletonema costatum. Limnol Oceanogr 45:1807-1817

> Barkmann W, Woods JD (1996) On using a Lagrangian model to calibrate primary production determined from in vitro incubation measurements. J Plankton Res 18:767-788

Behrenfeld MJ (2010) Abandoning Sverdrup's critical depth hypothesis on phytoplankton blooms. Ecology 91:977-989

Behrenfeld MJ, Prasil O, Kolber ZS, Babin M, Falkowski PG (1998) Compensatory changes in photosystem II electron turnover rates protect photosynthesis from photoinhibition. Photosynth Res 58:259-268

> Bienfang PK (1981) Sinking rates of heterogeneous, temperate phytoplankton populations. J Plankton Res 3:235-253

> Bienfang PK, Takahashi M (1983) Ultraplankton growth rates in a subtropical ecosystem. Mar Biol 76:213-218

> Broekhuizen N (1999) Simulating motile algae using a mixed Eulerian-Lagrangian approach: Does motility promote dinoflagellate persistence or co-existence with diatoms? J Plankton Res 21:1191-1216

Brown SL, Landry MR, Christensen S, Garrison D, Gowing MM, Bidigare RR, Campbell L (2002) Microbial community dynamics and taxon-specific phytoplankton production in the Arabian Sea during the 1995 monsoon seasons. Deep Sea Res II 49:2345-2376

> Calbet A, Landry MR (2004) Phytoplankton growth, microzooplankton grazing, and carbon cycling in marine systems. Limnol Oceanogr 49:51-57

> Cianelli D, D'Alcalá MR, Saggiomo V, Zambianchi E (2004) Coupling mixing and photophysiological response of antarctic plankton: a Lagrangian approach. Antarct Sci 16: 133-142 
Eilers PHC, Peeters JCH (1988) A model for the relationship between light intensity and the rate of photosynthesis in phytoplankton. Ecol Model 42:199-215

Eppley RW, Holmes RW, Strickland JDH (1967) Sinking rates of marine phytoplankton measured with a fluorometer. J Exp Mar Biol Ecol 1:191-208

Falkowski PG (1981) Light-shade adaptation and assimilation numbers. J Plankton Res 3:203-216

Falkowski PG (1983) Light-shade adaptation and vertical mixing of marine phytoplankton: a comparative field study. J Mar Res 41:215-237

Furnas M (1990) In situ growth rates of marine phytoplankton: Approaches to measurement, community and species growth rates. J Plankton Res 12:1117-1151

Furnas M (2002) Measuring the growth rates of phytoplankton in natural populations. In: Rao DVS, Rao S, Ganapati PN, Lafond EC, Humphrey GF (eds) Pelagic ecology methodology. CRC Press, Boca Raton, FL, p 221-249

Furuya K, Takahashi M, Nemoto T (1986) Summer phytoplankton community structure and growth in a regional upwelling area off Hachijo Island, Japan. J Exp Mar Biol Ecol 96:43-55

Gallegos CL, Platt T (1985) Vertical advection of phytoplankton and productivity estimates: a dimensional analysis. Mar Ecol Prog Ser 26:125-134

Geider RJ, MacIntyre HL, Kana TM (1998) A dynamic regulatory model of phytoplanktonic acclimation to light, nutrients, and temperature. Limnol Oceanogr 43:679-694

Gocke K, Lenz J (2004) A new turbulence incubator for measuring primary production in non-stratified waters. J Plankton Res 26:357-369

Gutiérrez-Rodríguez A, Latasa M, Estrada M, Vidal M, Marrasé C (2010) Carbon fluxes through major phytoplankton groups during the spring bloom and post-bloom in the northwestern Mediterranean Sea. Deep Sea Res I 57: 486-500

Han BP (2002) A mechanistic model of algal photoinhibition induced by photodamage to photosystem-II. J Theor Biol 214:519-527

Kagami M, Urabe J (2001) Phytoplankton growth rate as a function of cell size: an experimental test in Lake Biwa. Limnology 2:111-117

Köhler J (1997) Measurement of in situ growth rates of phytoplankton under conditions of simulated turbulence. J Plankton Res 19:849-862

Köhler J, Schmitt M, Krumbeck H, Kapfer M, Litchman E, Neale PJ (2001) Effects of UV on carbon assimilation of phytoplankton in a mixed water column. Aquat Sci 63: 294-304

Landry MR, Hassett RP (1982) Estimating the grazing impact of marine micro-zooplankton. Mar Biol 67:283-288

Landry MR, Kirshtein J, Constantinou J (1995) A refined dilution technique for measuring the community grazing impact of microzooplankton, with experimental tests in the central equatorial Pacific. Mar Ecol Prog Ser 120:53-63

Latasa M, Landry MR, Schlüter L, Bidigare RR (1997) Pigment specific growth and grazing rates of phytoplankton in the central Equatorial Pacific. Limnol Oceanogr 42:289-298

Latasa M, Morn XAG, Scharek R, Estrada M (2005) Estimating the carbon flux through main phytoplankton groups in the northwestern Mediterranean. Limnol Oceanogr 50: 1447-1458

> Lewis MR, Cullen JJ, Platt T (1984a) Relationships between vertical mixing and photoadaptation of phytoplankton: similarity criteria. Mar Ecol Prog Ser 15:141-149

Lewis MR, Horne EPW, Cullen JJ, Oakey NS, Platt T (1984b) Turbulent motions may control phytoplankton photosynthesis in the upper ocean. Nature 311:49-50
Lizon F, Seuront L, Lagadeuc Y (1998) Photoadaptation and primary production study in tidally mixed coastal waters using a Lagrangian model. Mar Ecol Prog Ser 169:43-54

Long SP, Humphries S, Falkowski PG (1994) Photoinhibition of photosynthesis in nature. Annu Rev Plant Physiol Plant Mol Biol 45:633-662

MacIntyre HL, Kana TM, Geider RJ (2000) The effect of water motion on short-term rates of photosynthesis by marine phytoplankton. Trends Plant Sci 5:12-17

MacIntyre HL, Kana TM, Anning T, Geider RJ (2002) Photoacclimation of photosynthesis irradiance response curves and photosynthetic pigments in microalgae and cyanobacteria. J Phytol 38:17-38

> Marra J (1978) Phytoplankton photosynthetic response to vertical movement in a mixed layer. Mar Biol 46:203-208

- Moore CM, Suggett DJ, Hickman AE, Kim YN and others (2006) Phytoplankton photoacclimation and photoadaptation in response to environmental gradients in a shelf sea. Limnol Oceanogr 51:936-949

- Nagai T, Yamazaki H, Kamykowski D (2003) A Lagrangian photoresponse model coupled with 2nd-order turbulence closure. Mar Ecol Prog Ser 265:17-30

> Öquist G, Chow WS, Anderson JM (1992) Photoinhibition of photosynthesis represents a mechanism for the long term regulation of photosystem II. Planta 186:450-460

Ptacnik R, Diehl S, Berger S (2003) Performance of sinking and nonsinking phytoplankton taxa in a gradient of mixing depths. Limnol Oceanogr 48:1903-1912

> Raven JA, Geider RJ (1988) Temperature and algal growth. New Phytol 110:441-461

Rhee GY, Gotham IJ (1981) The effect of environmental factors on phytoplankton growth: light and the interactions of light with nitrate limitation. Limnol Oceanogr 26: 649-659

Ross ON, Geider RJ (2009) New cell-based model of photosynthesis and photo-acclimation: accumulation and mobilisation of energy reserves in phytoplankton. Mar Ecol Prog Ser 383:53-71

Ross ON, Sharples J (2004) Recipe for 1-d Lagrangian particle tracking models in space-varying diffusivity. Limnol Oceanogr Methods 2:289-302

Ross ON, Sharples J (2007) Phytoplankton motility and the competition for nutrients in the thermocline. Mar Ecol Prog Ser 347:21-38

Ross ON, Moore CM, Suggett DJ, MacIntyre HL, Geider RJ (2008) A model of photosynthesis and photo-protection based on reaction centre damage and repair. Limnol Oceanogr 53:1835-1852

Ross ON, Geider RJ, Piera J (2011) Modelling the effect of vertical mixing on bottle incubations for determining in situ phytoplankton dynamics. II. Primary production. Mar Ecol Prog Ser 435:33-45

Sharples J, Moore CM, Rippeth TR, Holligan PM, Hydes DJ, Fisher NR, Simpson J (2001) Phytoplankton distribution and survival in the thermocline. Limnol Oceanogr 46: 486-496

Stolte W, Garcés E (2006) Ecological aspects of harmful algal in situ population growth rates. In: Granéli E, Turner JT (eds) Ecology of harmful algae, Vol. 189. Ecological Studies. Springer-Verlag, Berlin, p 139-152

> Suggett DJ, Moore CM, Hickman AE, Geider RJ (2009) Interpretation of fast repetition rate (FRR) fluorescence: signatures of phytoplankton community structure versus physiological state. Mar Ecol Prog Ser 376:1-19

Sukenik A, Bennett J, Falkowski P (1987) Light-saturated photosynthesis-limitation by electron transport or carbon fixation? Biochim Biophys Acta 891:205-215 
Waite A, Fisher A, Thompson PA, Harrison PJ (1997) Sinking rate versus cell volume relationships illuminate sinking rate control mechanisms in marine diatoms. Mar Ecol Prog Ser 157:97-108

Williams PJB, Heinemann KR, Marra J, Purdie DA (1983) Comparison of ${ }^{14} \mathrm{C}$ and $\mathrm{O}_{2}$ measurements of phytoplankton production in oligotrophic waters. Nature 305:49-50

Wolf KU, Woods JD (1988) Lagrangian simulation of primary production in the physical environment-the deep chlorophyll maximum and nutricline. In: Rothschild BJ (ed) Toward a theory in biological-physical interactions in the world ocean, NATO ASI Series C, Kluwer, Dordrecht, p 51-70

Woods JD, Onken R (1982) Diurnal variation and primary production in the ocean - preliminary results of a Lagrangian ensemble model. J Plankton Res 4:735-756

Appendix 1. Biological model parameters (Table A1) and equations (Table A2). This section provides a summary of the main biological model equations, containing the equations from Tables $3 \& 4$ from Ross \& Geider (2009) in their modified version used in this study, plus the additions for photoinhibition. See the model description in Ross \& Geider (2009) for a more detailed explanation of each equation

Table A1. Biological model parameters

\begin{tabular}{|c|c|c|c|}
\hline Symbol & Description & Value & Unit \\
\hline$a$ & Factor by which dark $N$ uptake rate is reduced & 0.75 & - \\
\hline$a^{C h l}$ & Chl a specific absorption coefficient & 6.56 & $\mathrm{~m}^{2} \mathrm{gChl}^{-1}$ \\
\hline$C^{F}$ & Functional C content & Eq. (24) & pgC cell ${ }^{-1}$ \\
\hline$C^{R}$ & Reserve C content & Eq. (25) & pgC cell ${ }^{-1}$ \\
\hline$C^{T}$ & Total C content (functional plus reserve) & $C^{F}+C^{R}$ & pgC cell ${ }^{-1}$ \\
\hline$C_{\mathrm{fis}}^{F}$ & Functional C content required for cell fission & 14 & pgC cell ${ }^{-1}$ \\
\hline$C_{\min }^{F}$ & Subsistence level in functional pool & $0.25 C_{\text {fis }}^{F}$ & pgC cell ${ }^{-1}$ \\
\hline$C_{\text {thres }}^{R}$ & C storage capacity to maintain cell through dark & $(24-L) R_{m}^{\text {cell }}$ & pgC cell ${ }^{-1}$ \\
\hline Chl & Amount in chlorophyll $a$ in cell & Variable & $\mathrm{gChl} \mathrm{cell}^{-1}$ \\
\hline$D I N$ & Dissolved inorganic nitrogen concentration & 500 & $\mathrm{mgN} \mathrm{m}^{-3}$ \\
\hline$I$ & Light intensity & Variable & $\mu \mathrm{mol}$ photons $\mathrm{m}^{-2} \mathrm{~s}^{-1}$ \\
\hline$I_{k}$ & Light saturation parameter & Variable & $\mu \mathrm{mol}$ photons $\mathrm{m}^{-2} \mathrm{~s}^{-1}$ \\
\hline$k_{r}$ & Repair rate from photoinhibition & $4.5 \times 10^{-5}$ & $\mathrm{~s}^{-1}$ \\
\hline$\kappa_{N}$ & Half-saturation for N uptake & 14 & $\mathrm{mgN} \mathrm{m}{ }^{-3}$ \\
\hline$L$ & Light period & 15 & $\mathrm{~h}$ \\
\hline$N$ & Cellular nitrogen & Variable & pgN cell ${ }^{-1}$ \\
\hline$P_{f}$ & Scaling factor & 1.5 & - \\
\hline$P_{\max }^{\text {cell }}$ & Max. cell-based C production & Variable & gC cell ${ }^{-1} \mathrm{~s}^{-1}$ \\
\hline$P_{m}^{c h l}$ & Max. Chl-based C production (with inhibition) & $P_{\max }^{c h l} \vartheta$ & $\mathrm{gC} \mathrm{gChl}^{-1} \mathrm{~s}^{-1}$ \\
\hline$P_{\max }^{c h l}$ & Max. Chl-based C production (without inhibition) & $3.3 \times 10^{-3}$ & $\mathrm{gC} \mathrm{gChl}^{-1} \mathrm{~s}^{-1}$ \\
\hline$P_{\max }^{F}$ & Max. $C^{F}$-based production at a given $Q$ & Variable & $\mathrm{s}^{-1}$ \\
\hline$P_{\max }^{C}$ & Max. $C^{T}$-based production at a given $Q$ & Eq. (19) & $\mathrm{s}^{-1}$ \\
\hline$Q$ & $\mathrm{~N}: \mathrm{C}$ ratio of entire cell & $N / C^{T}$ & $\mathrm{gN} \mathrm{gC}^{-1}$ \\
\hline$Q^{F}$ & $\mathrm{~N}: \mathrm{C}$ ratio of functional pool $\left(\equiv Q_{\max }\right)$ & 0.19 & $\mathrm{gN} \mathrm{gC}^{-1}$ \\
\hline$Q_{\min }$ & Min. $\mathrm{N}$ :C ratio of entire cell when $C^{R}$ is maximal & 0.05 & $g \mathrm{Ng} \mathrm{C}^{-1}$ \\
\hline$R_{m}^{\text {cell }}$ & Cell-based maintenance respiration & 0.05 & $\operatorname{pgC}(\text { cell d })^{-1}$ \\
\hline$T_{f}$ & Delay to complete cell division after reaching $C_{\text {fis }}^{F}$ & 2 & $\mathrm{~h}$ \\
\hline$V_{\max }^{N}$ & Max. N uptake rate & Eq. (23) & $\mathrm{gN}(\text { cell d })^{-1}$ \\
\hline$\alpha_{\max }^{C h l}$ & Initial slope of the P-I curve (without inhibition) & $6.3 \times 10^{-6}$ & $\mathrm{gC} \mathrm{m}^{2}$ (gChl $\mu \mathrm{mol}$ photons $)^{-1}$ \\
\hline$\Delta t$ & Model time step & $1-6$ & $\mathrm{~s}$ \\
\hline$\phi_{\max }$ & Max. quantum yield of photosynthesis & $0.96 \times 10^{-6}$ & $\mathrm{gC}(\mu \mathrm{mol} \text { photons })^{-1}$ \\
\hline$\phi_{m}$ & Achieved quantum yield when inhibited & Variable & $\mathrm{gC}(\mu \mathrm{mol} \text { photons })^{-1}$ \\
\hline$\mu_{\max }$ & Maximum specific growth rate & 1.15 & $\mathrm{~d}^{-1}$ \\
\hline$\Pi_{\max }^{L}$ & Max. prop. of $C^{F}$ allocated to light harvesting & 0.33 & - \\
\hline$\vartheta$ & Proportion of functional PSII reaction centres & $0 \leq \vartheta \leq 1$ & - \\
\hline$\sigma_{\text {PSII }}$ & Absorption cross-section of PSII & 1.5 & $\mathrm{~m}^{2}\left(\mu \mathrm{mol}\right.$ photons $\left.{ }^{-1}\right)$ \\
\hline$\theta^{C}$ & Chl:C ratio of cell & $\mathrm{Chl} / \mathrm{C}^{T}$ & $\mathrm{gChl} \mathrm{gC}^{-1}$ \\
\hline$\theta_{F}^{C}$ & Chl:C ratio for functional pool only & $C h l / C^{F}$ & $\mathrm{gChl} \mathrm{gC}^{-1}$ \\
\hline$\left(\theta_{L}^{C}\right)_{\max }$ & Max. Chl:C ratio in light-harvesting pool & 0.28 & $\mathrm{gChl} \mathrm{gC}^{-1}$ \\
\hline$\left(\theta_{F}^{C}\right)_{\max }$ & Max. Chl:C ratio in functional pool & $\left(\theta_{L}^{C}\right)_{\max } \Pi_{\max }^{L}$ & $\mathrm{gChl} \mathrm{gC}^{-1}$ \\
\hline$\zeta$ & Cost of biosynthesis & 3.0 & $\mathrm{gC} \mathrm{gN}^{-1}$ \\
\hline
\end{tabular}


Table A2. Biological equations

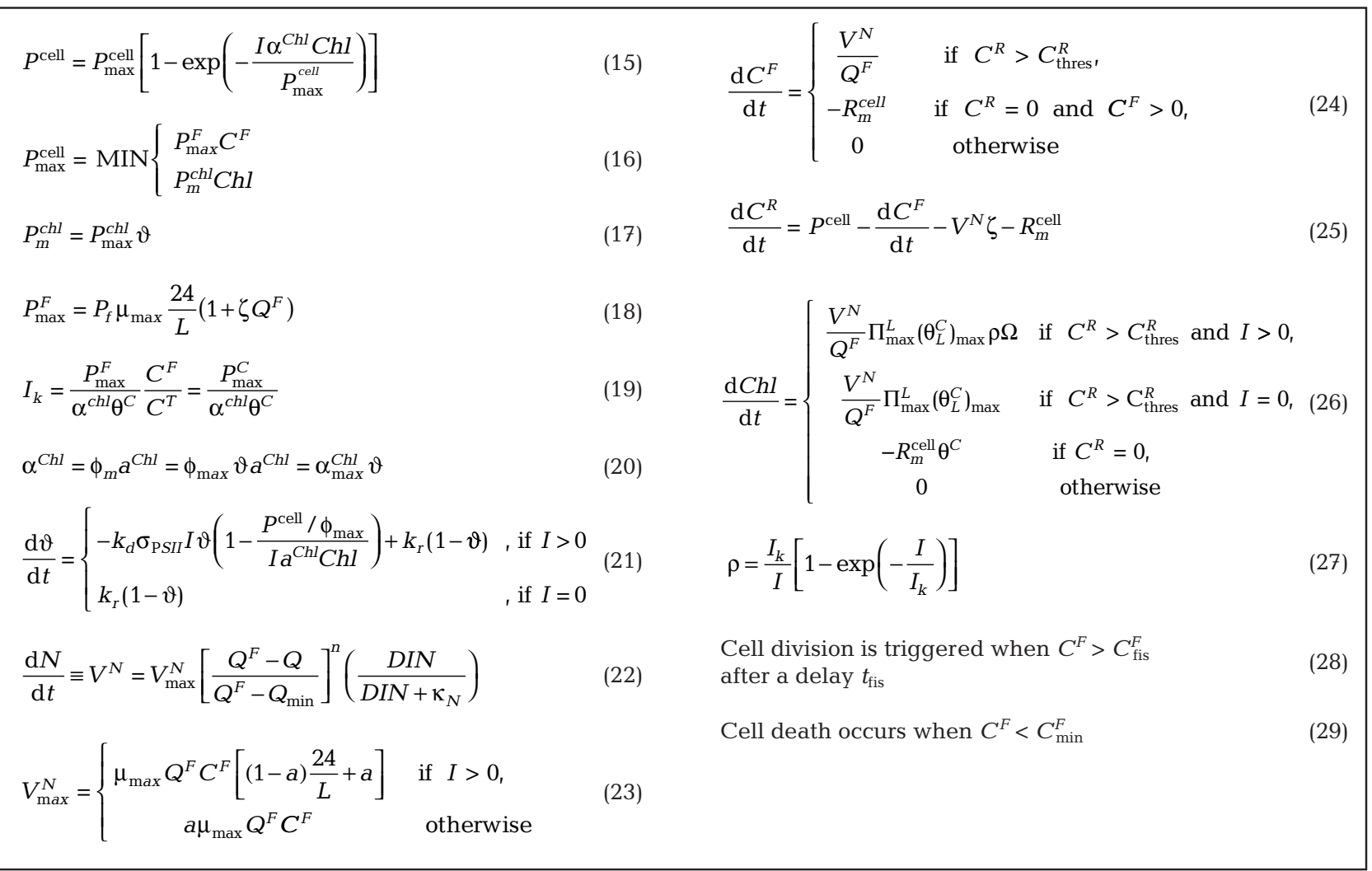

Editorial responsibility: Katherine Richardson, Copenhagen, Denmark
Submitted: September 30, 2010; Accepted: May 2, 2011

Proofs received from author(s): August 12, 2011 